R7

Printed March 1982

\title{
SIMMER Analysis of Prompt Burst Energetics Experiments
}

John T. Hitchcock

\section{Prepared by}

Sandia National Laboratories

Albuquerque, New Mexico 87185 and Livermore, California 94550

for the United States Department of Energy

under Contract DE-AC04-76DP00789

\section{Prepared for}

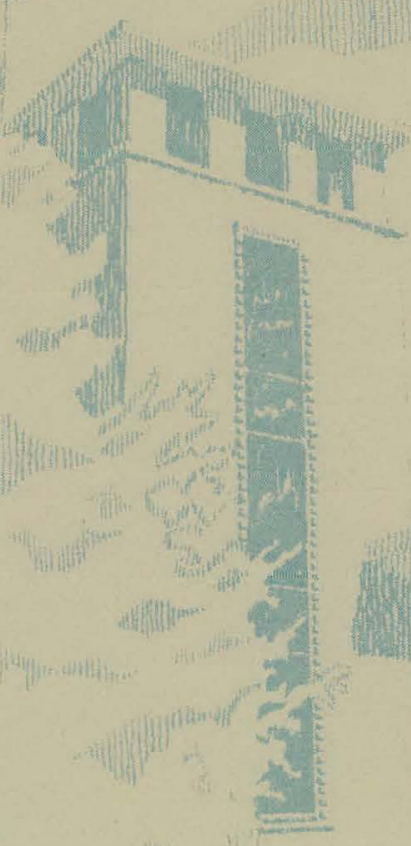




\section{DISCLAIMER}

This report was prepared as an account of work sponsored by an agency of the United States Government. Neither the United States Government nor any agency Thereof, nor any of their employees, makes any warranty, express or implied, or assumes any legal liability or responsibility for the accuracy, completeness, or usefulness of any information, apparatus, product, or process disclosed, or represents that its use would not infringe privately owned rights. Reference herein to any specific commercial product, process, or service by trade name, trademark, manufacturer, or otherwise does not necessarily constitute or imply its endorsement, recommendation, or favoring by the United States Government or any agency thereof. The views and opinions of authors expressed herein do not necessarily state or reflect those of the United States Government or any agency thereof. 


\section{DISCLAIMER}

Portions of this document may be illegible in electronic image products. Images are produced from the best available original document. 


\section{NOTICE}

This report was prepared as an account of work sponsored by an agency of the United States Government. Neither the United States Government nor any agency thereof, or any of their employees, makes any warranty, expressed or implied, or assumes any legal liability or responsibility for any third party's use, or the results of such use, of any information, apparatus product or process disclosed in this report, or represents that its use by such third party would not infringe privately owned rights.

Available from

GPO Sales Program

Division of Technical Information and Document Control

U.S. Nuclear Regulatory Commission.

Washington, D.C. 20.5 .5 .5

and

National Technical Information Service

Springfield, Virginia 22161 


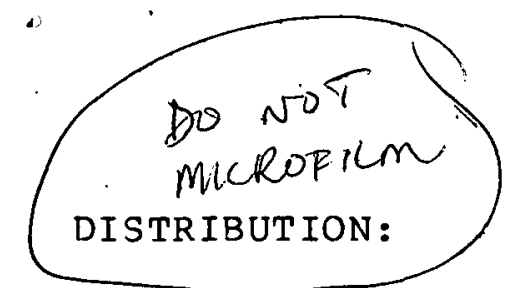

US NRC Distribution Contractor (CDSI) ( 300 copies)

7300 Pearl street

Bethesda, MD 20014

275 for copies for R7

25 copies for NTIS

General Electric Corporation

310 DeGuigne Drive

Sunnyvale, CA 94086

Attn: D. M. Switick

C. R. Bell, Q7, LASL

J. H. Scott, Q7, LASL

L. L. Smith, Q7, LASL

4000 A. Narath

4400 A. W. Snyder

4410 D. J. McCloskey

4420 J. V. Walker

4420 D. Sobl ick

4421 R. L. Coats (2)

4421 J. T. Hitchcock (10)

4422 D. A. Powers

4423 P. S. Pickara

4423 K. O. Reil

4424 M. J. Clauser

4424 P. J. McDaniel

4424 P. E. Rexroth

4425 W. J. Camp

4425 E. D. Bergeron

4425 F. Briscoe

4425 R. J. Lipinski

4424 J. E. Kelly

4425 K. K. Murata

4425 A. Suo-Anttila

4425 M. F. Young

4426 G. L. Cano

$4450 \mathrm{~J}$. A. Reuscher

4451 T. R. Schmidt

4452 M. Aker

4453 W. J. Whitfield

8214 M. A. Pound

3141 L. J. Erickson (5)

3151 W. L. Garner (3) 
NUREG/CR-2473

SAND81-0933

R7
This report was prepared as an account of work sponsored by an agency of the United States Government.

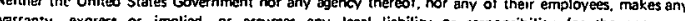

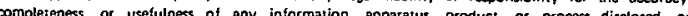
represents that its use would not infringe privately owned rights. Aaference herein 10 any spocitie commercial product. process, or secvice by trade name, trademark, manufacturar, or otherwise, doos not necessorily constitute or imply its endorsement, recommendation, or favoring by the united States Government or any agency thereof. The views end opinions of authors expressed herein do not necessarily state or reflect those of the United States Government or any agency thereof.

SIMPER ANALYSIS OF PROMPT BURST ENERGETICS EXPERIMENTS

J. T. Hitchcock

NUREG/CR--2 173

DE82 016280

Sandia National Laboratories Albuquerque, New Mexico 87185 operated by

Sandia Corporation

for the

U.S. Department of Energy

Manuscript Submitted: October 1981

Date Published: March 1982

\begin{abstract}
The Prompt Burst Energetics experiments are designed to measure the pressure behavior of fuel and coolant as working fluids during a hypothetical prompt burst disassembly in an LMFBR. The work presented in this report consists of a parametric study of PBE-5S, a fresh oxide fuel experiment, using SIMMER-II. The various pressure sources in the experiment are examined, and the dominant source identified as incondensable contaminant gasses in the fuel. The important modeling uncertainties and limitations of SIMMER-II as applied to these experiments are discussed.
\end{abstract}

\footnotetext{
Prepared for

Division of Reactor Safety Research

Office of Nuclear Regulatory Research

U.S. Nuclear Regulatory Commission

washington, DC 20555

Under Memorandum of Understanding DOE 40-550-75

NRC FIIJ WO. A-1181
} 


\section{INTRODUCTION}

The Prompt Burst Energetics (PBE) experiments ${ }^{l}$ are a series of in-pile tests conducted at Sandia National Laboratories in the Annular Core Pulse Reactor ( $A C P R$ ) and more recently in the Annular Core Research Reactor (ACRR). These experiments are designed to evaluate the pressure behavior of fuel and coolant as working fluids during a hypothetical prompt burst disassembly in an LMFBR. Herein is presented analyses of PBE-5S, a fresh oxide fuel experiment. These analyses have been performed with the SIMMER-II accident-analysis computer code developed at Los Alamos National Laboratory.

The purpose of the SIMMER PBE analysis program is threefold: (1) to investigate the usability of SIMMER in analyzing these complex experiments, (2) to provide insight into the separate pressure-generation and pressure-quenching mechanisms, and finally (3) to provide information for model development and verification for the ongoing sIMMER evaluation effort.

A SIMMER analysis of the PBE experiments is of special interest because of the lack of appropriate data for use in evaluating the heat transfer and energy conversion modeling in SIMMER, especially the liquid/liquid heat transfer. To date most of the SIMMER validation effort has concentrated on the fluid dynamics, and it was felt that the PBE series could provide a large data base with dominant energy transfer mechanisms. The question of the usability of SIMMER to analyze these experiments arises because SIMMER was created as a predictive tool for whole core phenomena. Both the geometric setup of the code and the level of detail is most appropriate for use on large scale problems.

of principal interest in this study are the details of disassembly, especially the processes and rates of energy exchange. However, the primary experimental diagnostics are pressure transducers located in the pressure vessel above and below the fuel pin - far away from the failure location and interaction zone. A mechanistic computer code, such as SIMMER, is required to predict the behavior in the interaction zone and to calculate the system response at the transducer locations. Comparisons can be made of the predicted and measured pressure histories at these locations to indicate successful modeling of the dominant processes. However, there may be no unique, best combination of code parameters and "experiment model" for fitting the data.

The work presented in this report consists of a parametric study of PBE-5S using SIMMER-II. The PBE-5S experiment has been chosen from the set of PBE experiments for analysis because of its relatively "clean" behavior as well as the fact that it typifies the series. The pressure events at the different transducer locations track one another, indicating that no significant channel blockages occur. 
In the current study the various pressure sources are identified and the effects on the computed results of changes in the initial conditions and in the nominal SIMMER models are investigated. The dominant pressure source in PBE-5S appears to be incondensible contaminant gasses in the fuel. Neither $\mathrm{NO}_{2}$ or sodium vapor pressure, alone or in combination, can provide the observed high initial pressure peaks coupled with the rapid decay.

A further result of the study is the identification of important modeling uncertainties and linitations in SIMMER-II. SIMMER-II, even though one of the most powerful deterninistic hydrocodes, has enough modeling uncertainties -- e.g., exchange coefficients, phase change rates and Eulerian mesh-cell diffusion -- and outright oversimplifications --.e.g., twodimensional geometry, temperature-independent properties, neglect of important condensation processes and neglect of liquid-liquid slip - - that detailed and unique experiment analysis is probably impossible. The hydrodynamics models in SIMMER-II are shown herein to provide a reasonable model for channel hydrodynamics in PBE-5S. The heat transfer models in SIMMER are the least well-founded and least-tested in the code.

\section{DESCRIPTION OF PBE-5S}

PBE-5S was one in a series of fresh $\mathrm{UO}_{2}$ experiments conducted in Sandia Laboratories' ACPR to investigate energetics and fuel failure phenomena under prompt burst conditions. In this experiment a single fresh $\mathrm{UO}_{2}$ fuel pin, $14 \%$ enriched, was failed using a single maximum pulse in the ACPR. The resulting peak axial energy deposition was about. $2350 \mathrm{~J} / \mathrm{g}$. However, because the neutron spectrum in the experiment was nonprototypically soft, the radial energy deposition profile, and thus the temperature profile at iailure, was peaked at the outer edge of the pin.

The fuel pin, clad in stainless steel with wire wrap, was contained in a sodium-filled, fluted channel within an external pressure vessel. The fluted channel was intended to simulate the geometry of six adjacent fuel pins in a reactor subassembly. The upper channel boundary was a movable piston that served as an inertial constraint on the system and provided an estinate of the thermal-to-mechanical energy conversion efficiency. Therrnocouples, adjacent to the top, center, and bottorn of the fuel pin, monitored temperatures in the sodium channel. pressure tranducers were located in the pressure vessel above and below the fuel pin. During the experiment, histories of the pressure, piston displacement, sodium temperatures, and reactor power were obtained. A detailed description of the experiment package can be found in Reference 1 .

A schematic of the fuel pin is shown in Figure 1. The pin contained a $344 \mathrm{~mm}$ long, 14 응 enriched $\mathrm{UO}_{2}$ fuel column bounded by depleted $\mathrm{UO}_{2}$ insulator pellets. The pin was helium bonded 


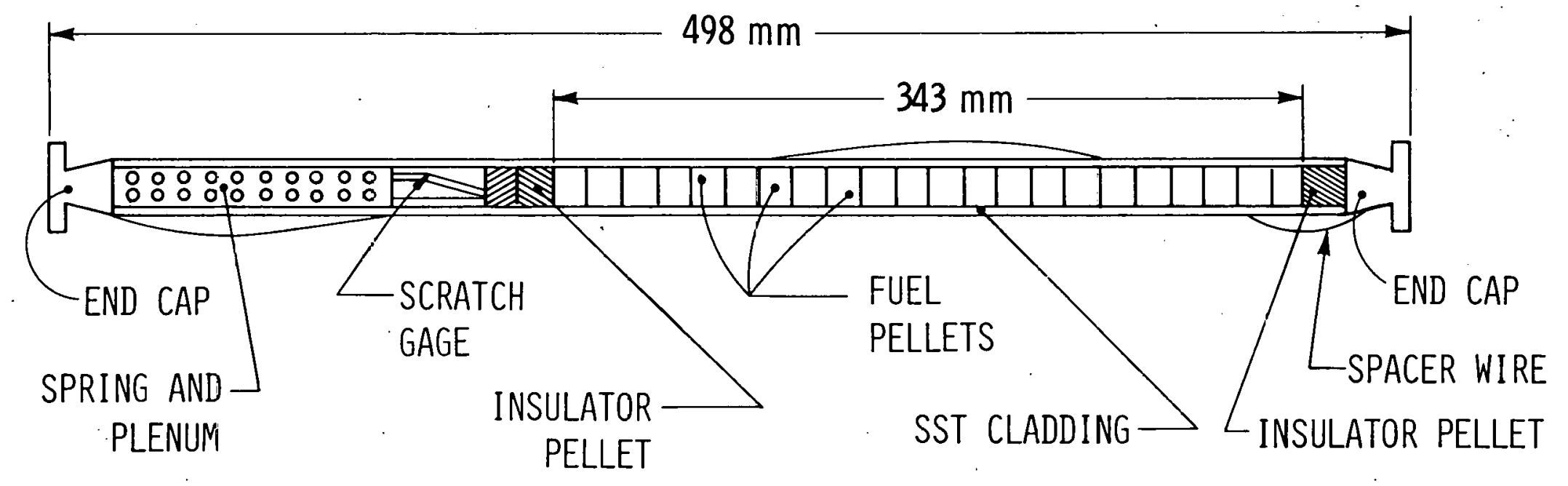

Figure 1. PBE Fresh $\mathrm{UO}_{2}$ Fuel Pin. 
(1. atmosphere pressure at room temperature.). A gas plenum containing a spring was. located at the upper end of the pin. The spring exerted a small force $(\sim 18 \mathrm{~N})$ on the scratch gauge and could accommodate approximately $50 \mathrm{~mm}$ of axial expansion. The characteristics of the fuel pin are summarized in Table 1.

Figure 2 shows a cross-section of the fueled portion of the PBE experiment capsule. The fuel pin was surrounded by a sodium annulus bounded by a molybdenum liner which simulated the geometry of six adjacent fuel pins and served as a refractory 1 iner for the Inconel pressure vessel. A helical wirewrap spacer was included between the pin and liner. The spaces between tha liner and pressure vessel were filled with sodium.

Figure 3 illustrates the important features of the assembled capsule and the location of the instrumentation.

TABLE I. PBE-5S Fuel Pin Characteristics

Fuel Pellets

Material

Enrichment

Diameter

Density

$14 \%$

$4.93 \mathrm{~mm}$

$89.98 \mathrm{TD}$

Insulator Pellets

Material

Enrichment -

$\mathrm{UO}_{2}$

Diameter.

Length

$4.93 \mathrm{~mm}$

Density

$6.35 \mathrm{~mm}$

$94.5 \%^{\circ} \mathrm{TD}$

Cladding

Material

Outside Diameter

316 SS

Clad Thickness.

$5.83 \mathrm{~mm}$

$0.38 \mathrm{~mm}$

Wire Wrap

Material

$316 \mathrm{sS}$

Diameter

$1.39 \mathrm{~mm}$

Pitch

$305 \mathrm{~mm}$

Total Fuel Mass

Total Fuel Length

$64 \mathrm{~g}$

Planar Smear Density

$343 \mathrm{~mm}$

Plenum. Length

$84.7 \%$ TD

Spring Solid.Height

$90 \mathrm{~mm}$

$34.9 \mathrm{~mm}$ 


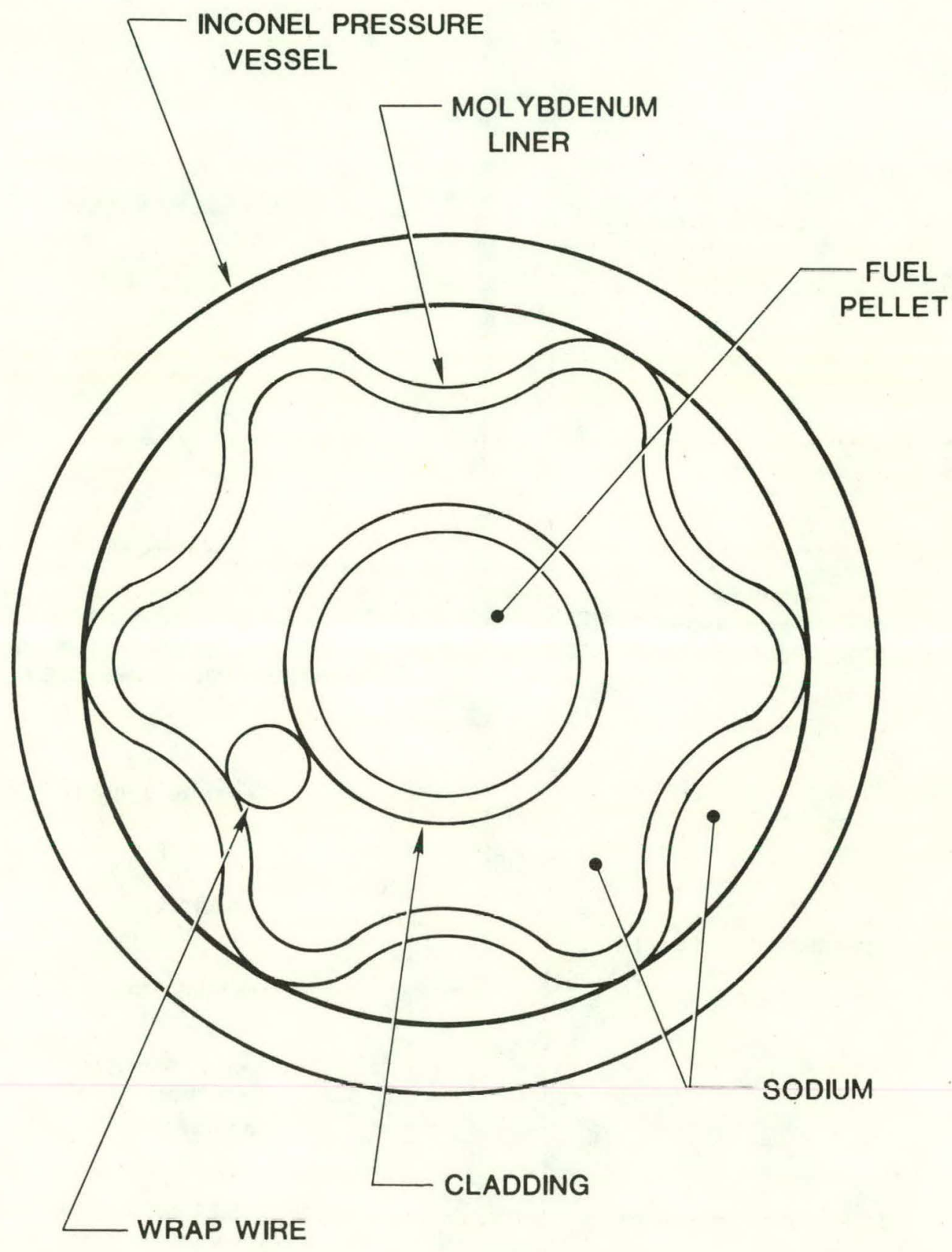

Figure 2. Cross-Section of Fueled Portion of PBE Experiment 


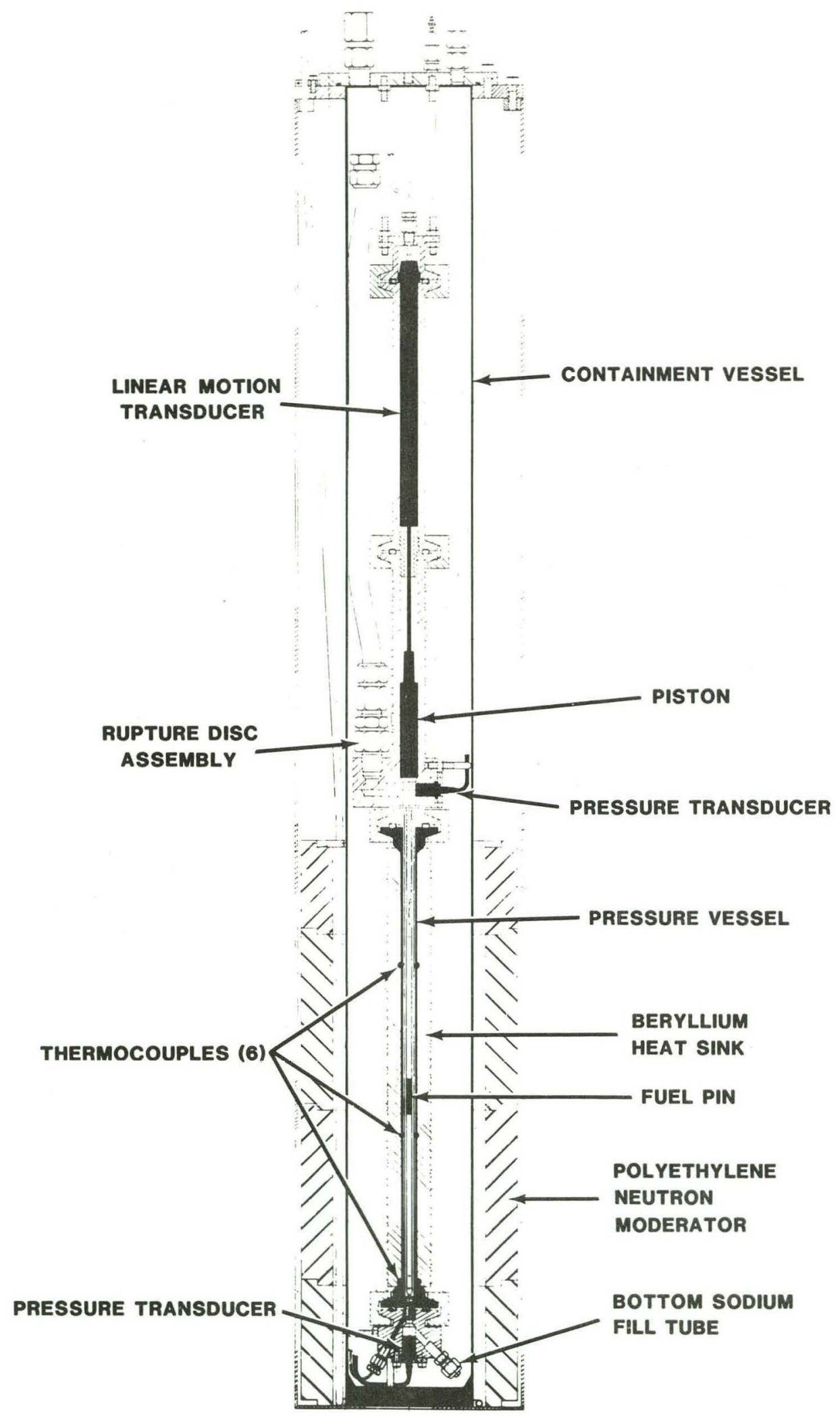

Figure 3. Prompt Burst Energetics Experiment Assembly 
Data taken during the PBE experiments included time histories of the coolant plenum pressures above and below the fuel pin, the channel sodium temperature at the bottom, middle, and top of the fuel pin, the piston displacement, and the reactor power. The axial location of these diagnostics was as indicated in Figure 3. The measured data histories are illustrated in Figures $4-6$.

The reactor power pulse, shown in Figure 4, deposited an average of $2025 \mathrm{~J} / \mathrm{g}$ in the test pin with a radially averaged, axial peak deposition of $2350 \mathrm{~J} / \mathrm{g}$. The radial deposition profile was calculated using $1-D$ discrete ordinate transport theory. The peak/average deposition ratio was calculated to be 1.22 with the peak occurring at the outer edge of the pin. The axial profile was experimentally determined by test pellet dosimetry. The axial peak/average ratio was thus found to be 1.16 . The experimenter estimated an uncertainfy of 5-8\% on the magnitude and shape of the energy deposition.

The measured pressure traces along with the piston displacement history are shown in Figure 5. The oscillatory nature of the pressure trains is a result of channel acoustics and the separation of the pressure source and the pressure data recording location. At the bottom transducer location a peak pressure of $47 \mathrm{MPa}$ is observed which decays to $1 \mathrm{MPa}$ within $4 \mathrm{~ms}$. Piston relief lowers the peak top pressure to $31 \mathrm{MPa}$. The lower pulse frequency at the top indicates a longer acoustic path length between the pin failure location and the transducer. It can be observed that the measured pressure at the top of the pressure canister goes negative at about $3 \mathrm{~ms}$ past pin failure. This is due to thermal gradients across the transducer face as hot material streams up the channel with piston motion. The shape of the curve is considered to be correct but a thermal drift begins at some unknown time and affects the normalization. After the $r$ apid transients have decayed, the two transducers should track each other, and the bottom transducer should provide a reasonable estimate of the pressure throughout the capsule.

Judqing from the amplitude and character of the measured pressure traces in this experiment, the dominant pressure source first appeared to be fuel vapor. There was a high initial peak followed by a rapid decay with no sustained pressure. If sodium vapor had provided the major contribution to the pressure, one would have expected a slower decay. However, uncertainties in the fuel equation-of-state and in the energy exchange processes involved, could mask a substantial contribution from sodium vapor pressure.

The uncertainty on the pressure transqucer data was estimated by the experimenter to he ahout $15 \% .3$ The transducers were statically calibrated at both $250 \mathrm{C}$ and $550 \mathrm{C}$. The accuracy of their dynamic behavior is currently under investigation. 

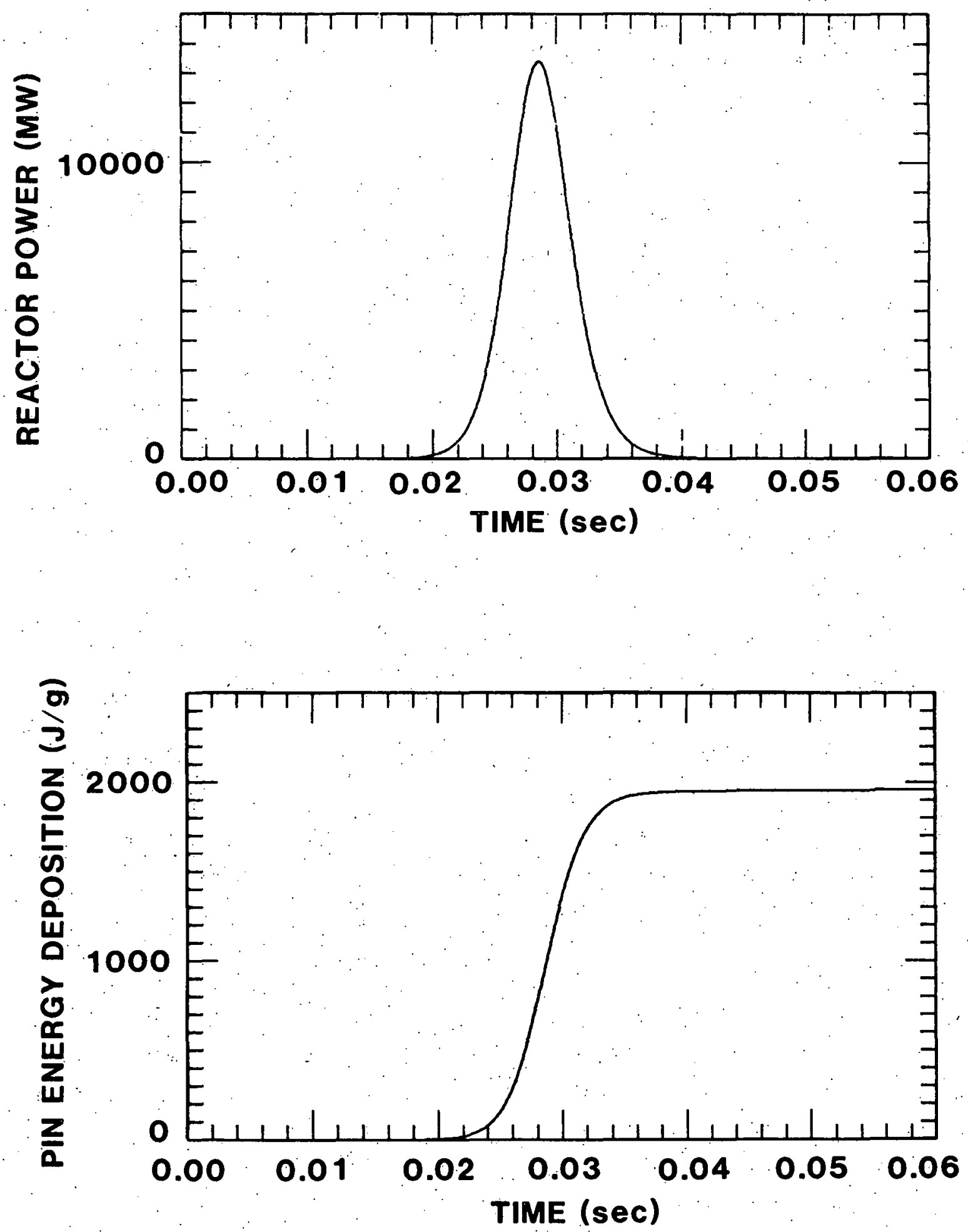

Figure 4. PBE- $5 S$ Power History and Pin Energy Deposition (Radial Average at Axial Peak) 

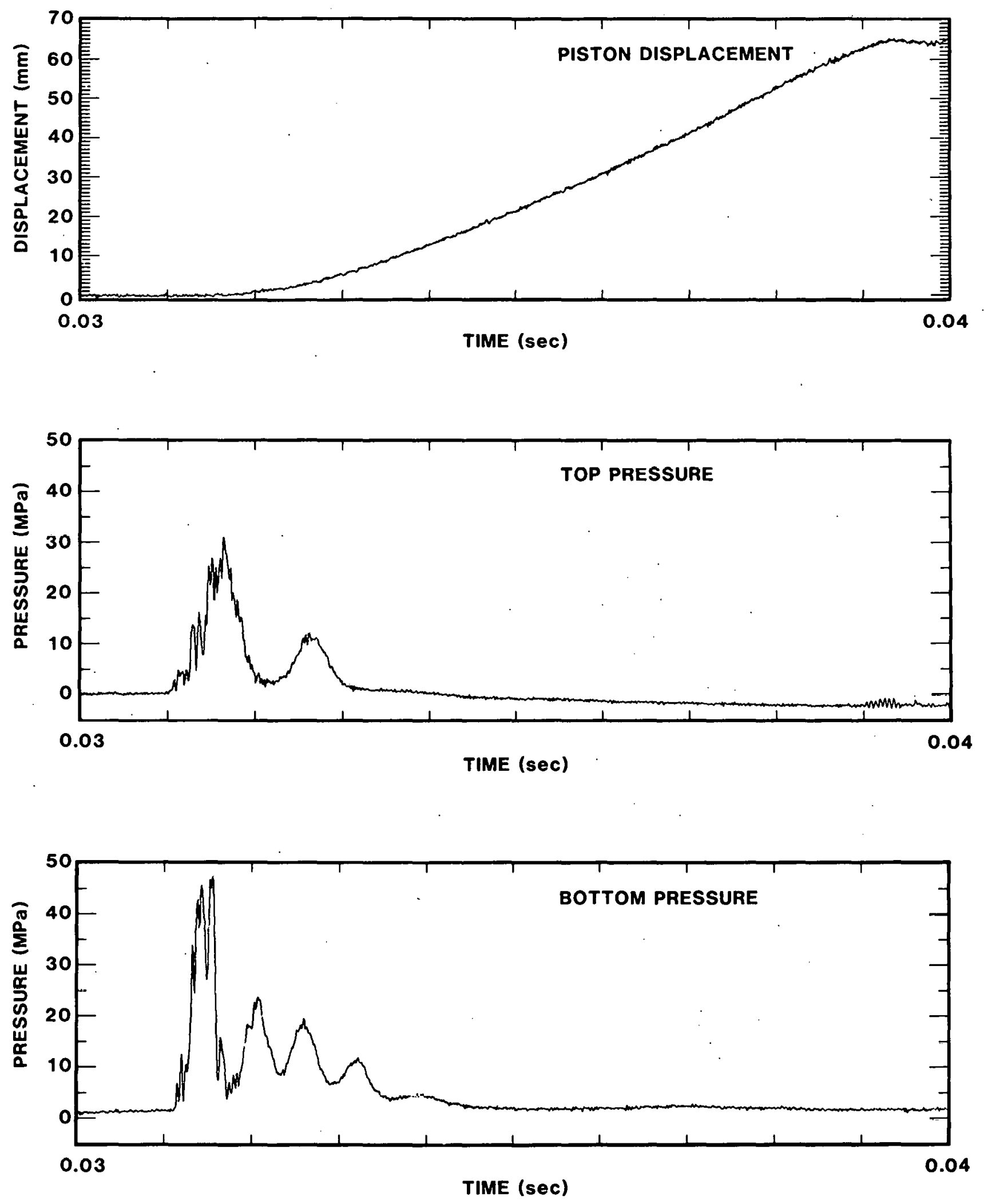

Figure 5. PBE-5S Data Histories 

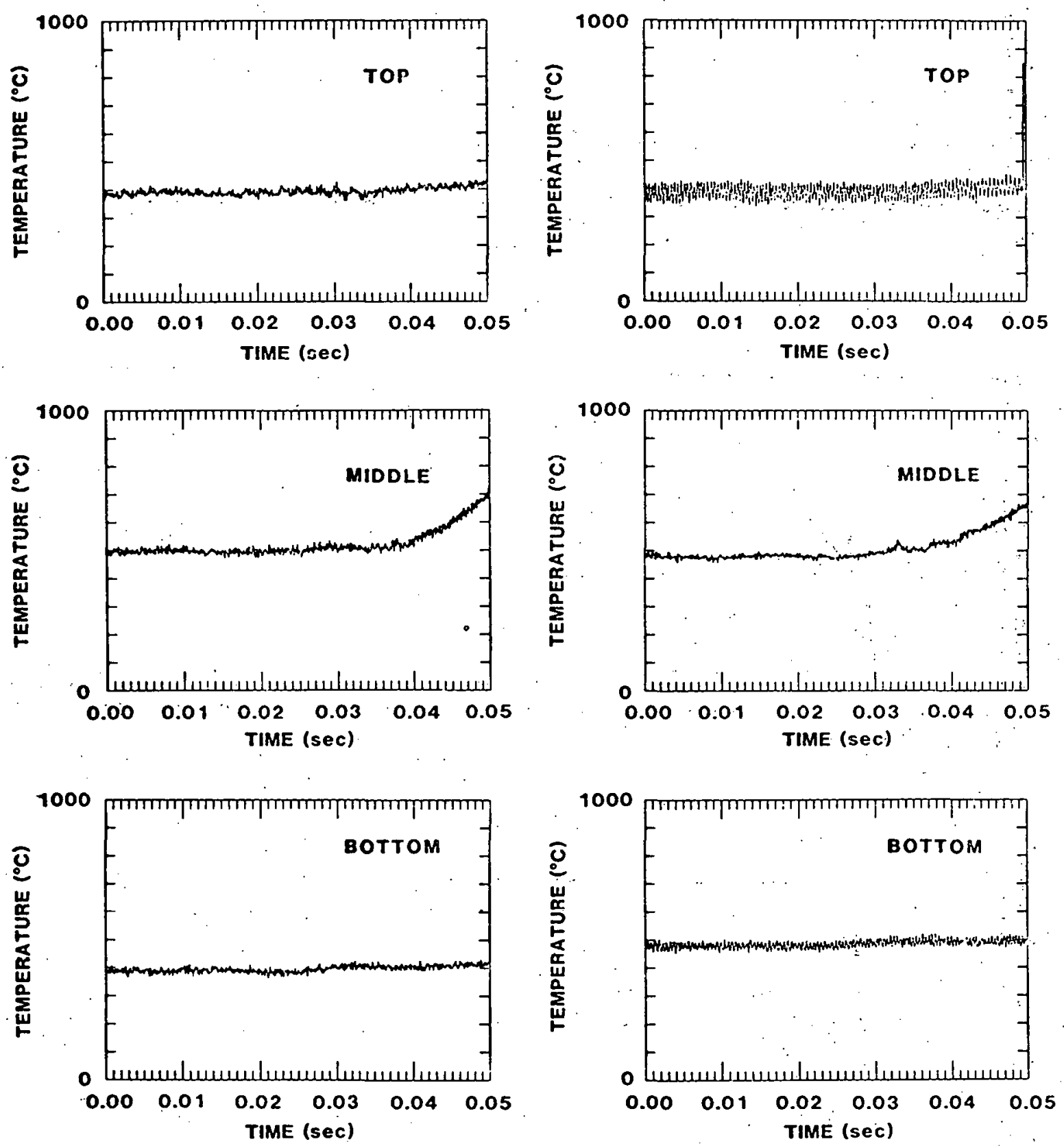

Figure 6. PBE-5S Thermocouple Histories 
Of the various diagnostics the linear motion detector is felt to have the smallest uncertainty. The total travel was verified in the post-experiment $r$ adiographs and thermal expansion effects during the transient were estimated to be no more than about

Since comparisons will be made between calculated and measured values, it is of interest to examine the consistency of the measured data. A comparison of data from the linear motion detector and the top pressure transducer was obtained by twice integrating the pressure data to derive a piston displacement under frictionless conditions. To do so, an estimated temperature drift correction has been applied to the measured pressure before integrating to compensate for the effects of the thermal gradients across the transducer face. This adjusted top pressure along with a comparison of the derived and measured piston displacements are shown in Figure 7. It is observed that the measured displacement is substantially less than what would be expected from the indicated pressures. The reason for this discrepancy may be that the pressure at the transducer location in the experiment was greater than at the piston face, or that there were resistive forces acting. on the piston, or that the dynamic readings of the transducer were high. Through sensitivity studies done as a part of this work it has been found that a best fit could be obtained by assuming that the piston sticks for about the first half millisecond. This calculation is also illustrated in Figure 7 .

The final diagnostic information comes from thermoccuples placed in the flutes of the sodium channel. Two thermocouples were placed opposite each other at each of the three axial positions indicated in Figure 3. Since the thermal response time to increasing sodium temperature is about $25 \mathrm{~ms}$, this diagnostic is only used in this study to provide an indication of the presence of liquid fuel in the channel. (An immediate step change in temperature should be observed if liquid fuel hits a thermocouple.) The data, displayed in Figure 6 , are not definitive. No rapid increase in temperature was observed immediately following pin failure. This may indicate the absence of liquid fuel in the channel (i.e., only fuel vapor exited the pin) or it may result from a break location above or azimuthally displaced from the thermocouple location, or a thick protective sodium film.

Before the discussion of the analysis of PBE-5S, it is instructive to evaluate the repeatability of the PBE experiments. Some perspective can be obtained from an examination of pressure data from 2 sets of identical experiments: PBE-4S/PBE-5S and PBE-6S/PBE-7S. From this data it is apparent that stochastic processes come into play.

PBE-4S was identical to pressure rupture disk failed the experiment relieving the PBE-5S, except that in PBE-4S a at the top of the capsule during pressure near the upper transducer. 

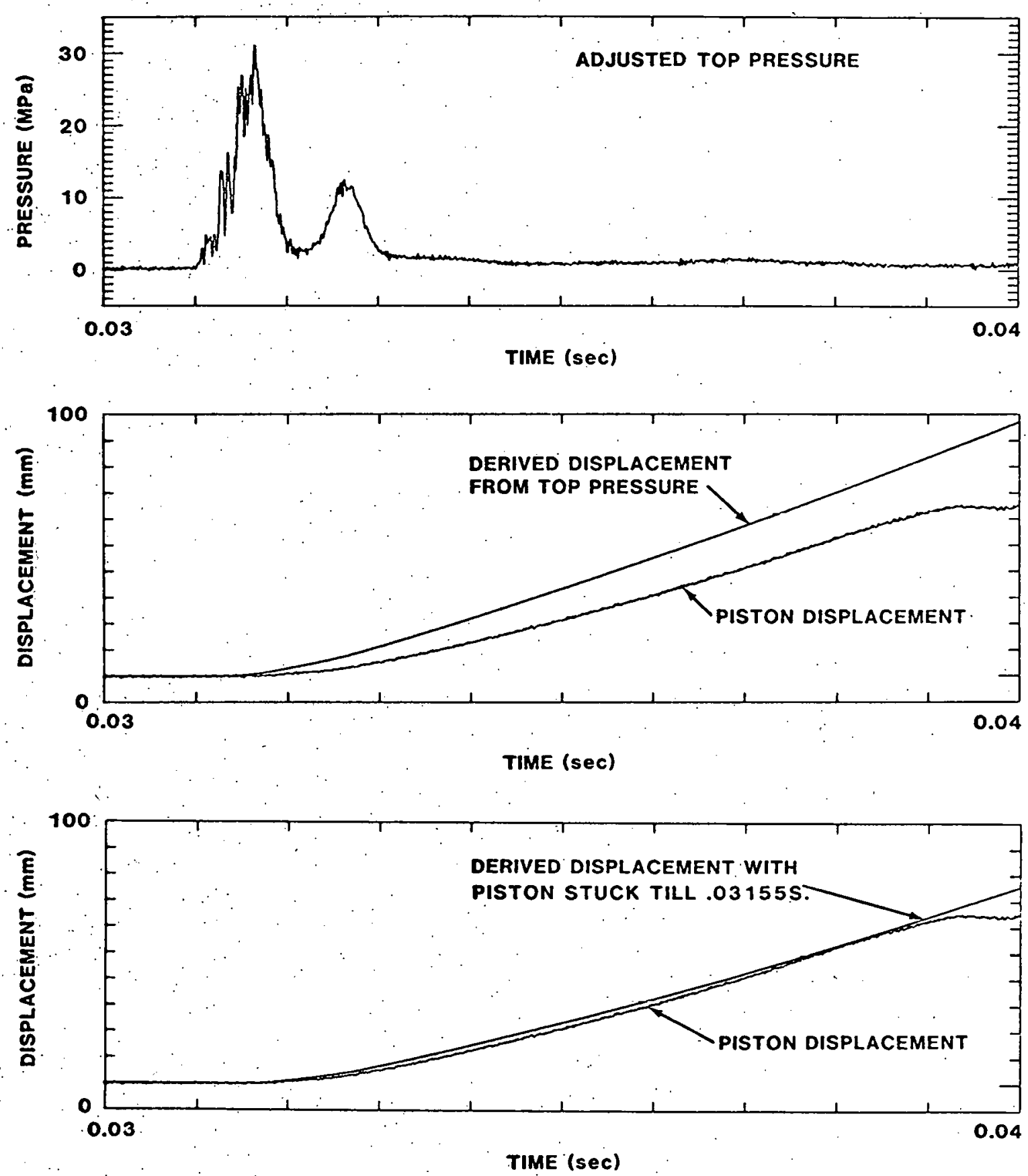

Figure 7. Derived and Measured PBE-5S Displacement Histories 
The pressure histories from the two experiments are shown in Figure 8. The characteristics of the bottom pressure traces, which should be relatively independent of the rupture disc problem, are very similar. The pressure decay in PBE-4S is slightly faster and there is a lower sustained pressure, but these differences are explained by the failed rupture disc.

The second set of identical experiments, $\mathrm{PBE}-6 \mathrm{~S}$ and $\mathrm{PBE}-7 \mathrm{~S}$, contained $20 \%$ enriched pins in order to examine the effects of higher fuel energy deposition. In these experiments the radially averaged axial peak deposition was $2900 \mathrm{~J} / \mathrm{g}$ compared to $2350 \mathrm{~J} / \mathrm{g}$ in $\mathrm{PBE}-5 \mathrm{~S}$. The piston displacement and pressure histories for $\mathrm{PBE}-6 \mathrm{~S}$ and $\mathrm{PBE}-7 \mathrm{~S}$ are shown in Figures 9 and 10 , respectively. From the shape and the frequency components of these pressure traces it appears that pressure sources different from those in PBE-5S were operative. The character of the top transducer data is different from the other experinents with an apparently random timing of the large pressure events. The bottom transducer data in PBE-7S appears to be similar to previous experiments, but considerably different frorn PBE-6S. Finally, in PBE-7S there is unexplained early piston movenent.

After examining this data base, one must conclude that significant variations in system response are possible. Furthermore, since each of these experiments was repeated only once, it is unlikely that the full range of behavior has been observed. This potential range of behavior must be kept in aind when conparing calculations to these measurements.

IV. SIMMER ANALYSIS

Introduction

The primary difficulty in analyzing the PBE experiments is the lack of detailed experimental diagnostics of phenomenologies being investigated. These are integral experiments in the sense that there are several coincident phenomena. Eut there are no measurements of the details of disassembly: there are no data on the pressures within the pin, the mode or extent of the clad failure, mixing, fuel motion or the interacting masses. In light of these limitations, the analysis consists of parametric model variations including changes to the geometry, initial conditions, material properties, and heat transfer rates.

SIMMER-II is a two-dimensional ( $R, z$ geometry), multiphase, multicomponent Eulerian computer code developed to analyze the coupled neutronic and fluid dynamic behavior of an LMFBR during a core disruptive accident. For the analysis of the PBE experiments only the fluid dynamic and heat transfer modules are utilized as the neutronic feedback to the reactor is negligible. since the main objective of the program was to investigate the phenomena which dominate the conversion of thermal energy to 

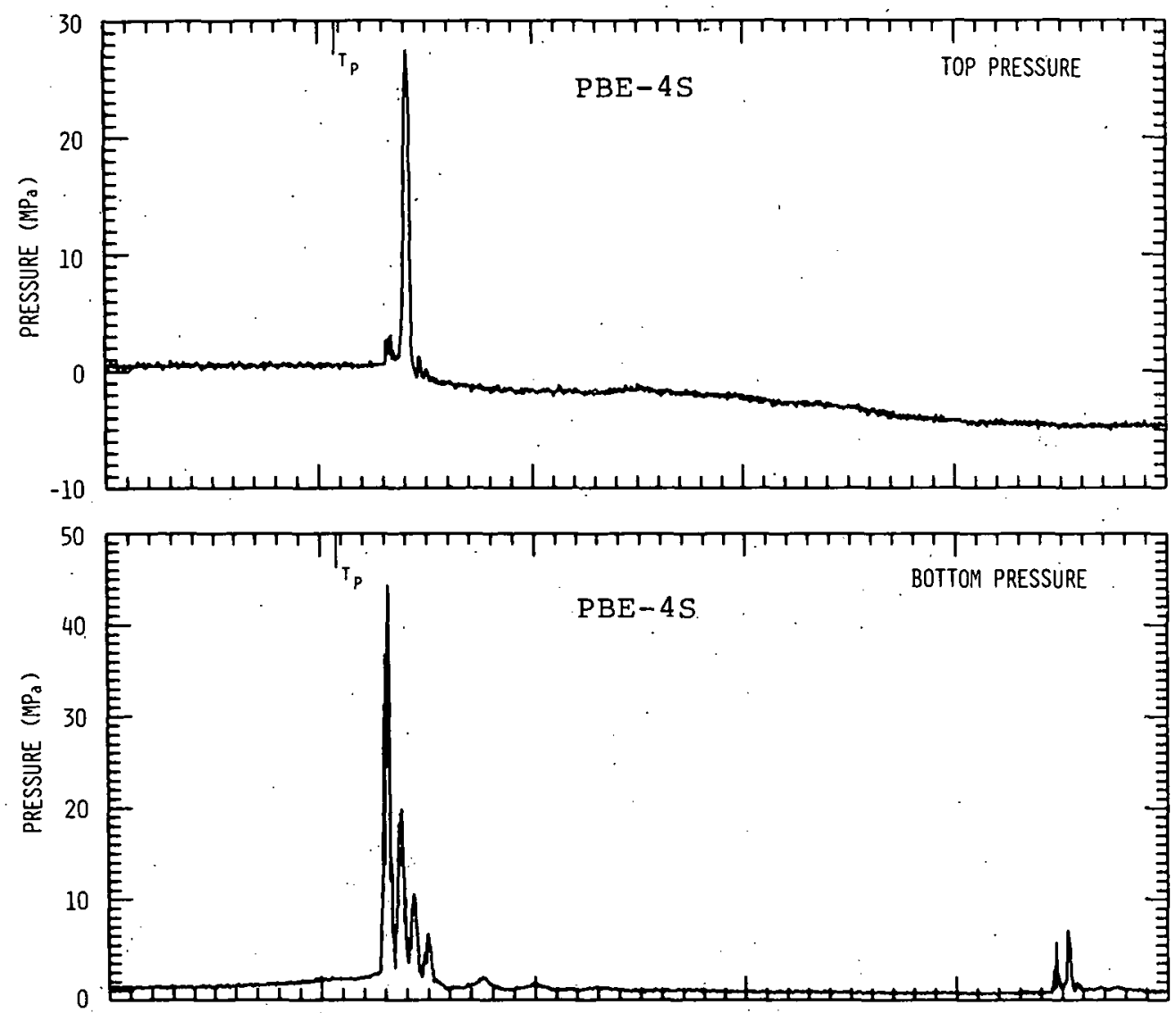

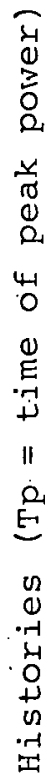

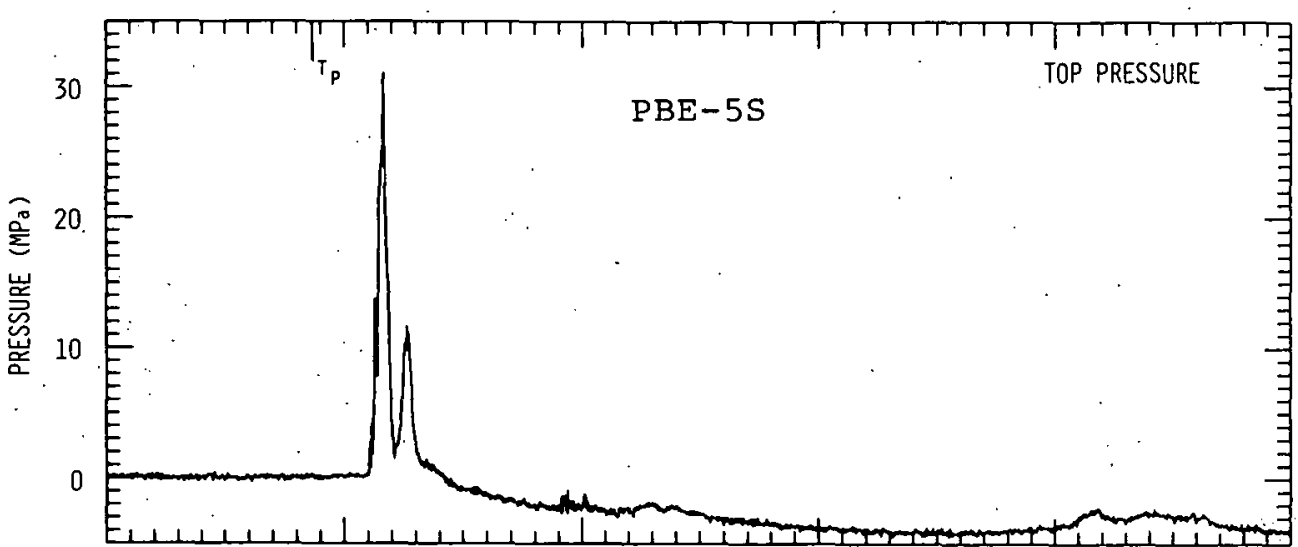

草

in

in

a

总

$n$
1
1
0
0
0

$\infty$

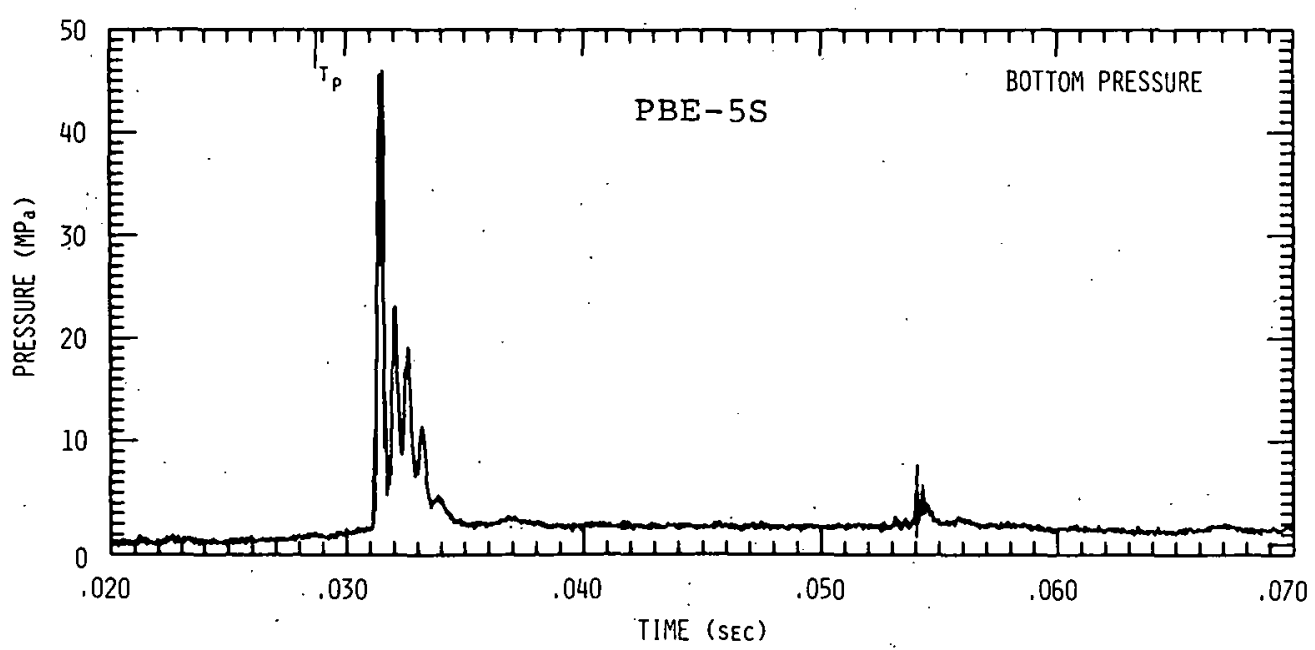

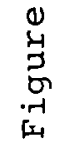



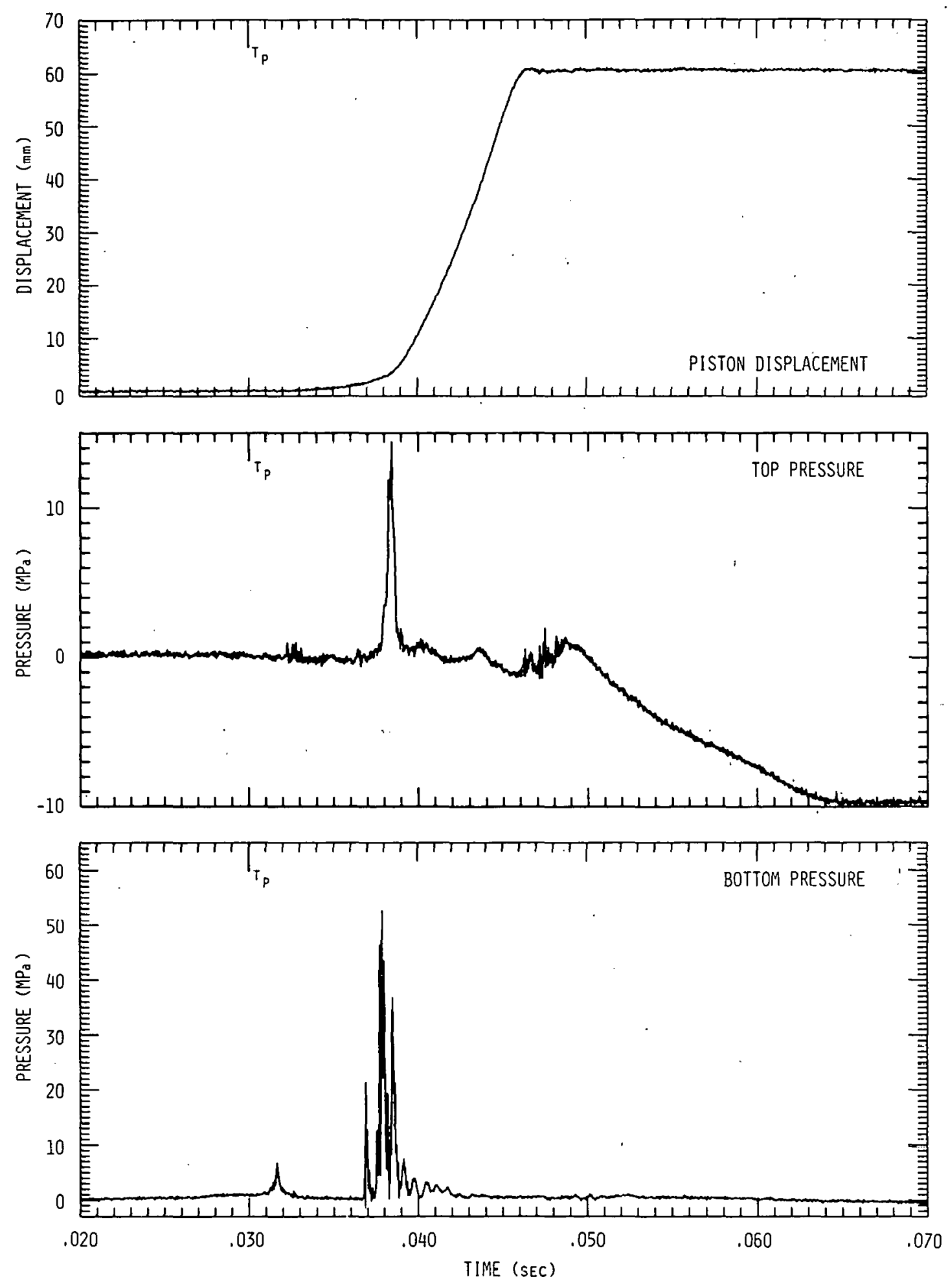

Figure 9. $\mathrm{PBE}-6 \mathrm{~S}$ Data Histories ( $\mathrm{Tp}=$ time of peak power) 

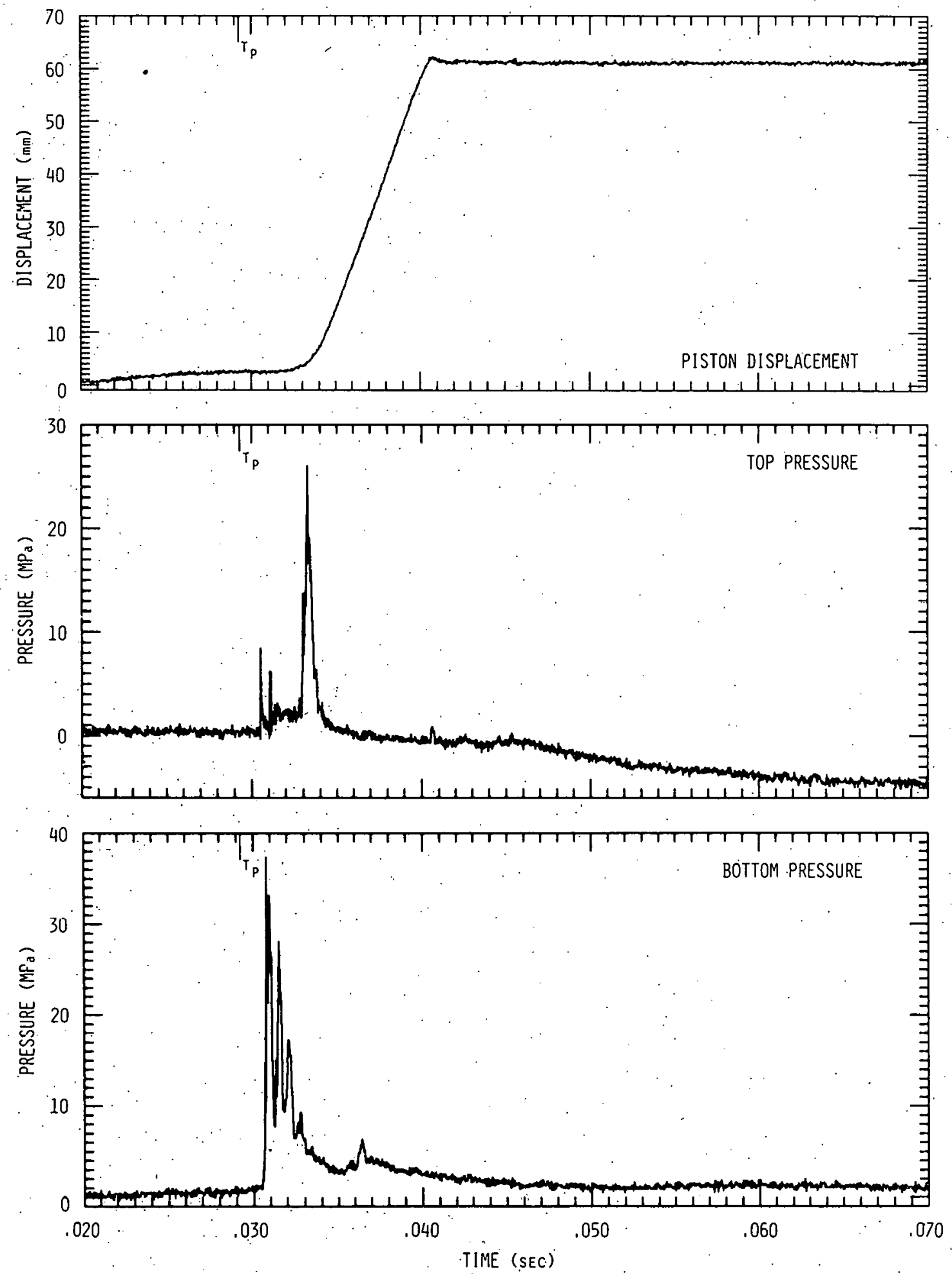

Figure 10. PBE-7S Data Histories (TP = time of peak power) 
work, the processes which control and characterize the various pressure sources and decay must be carefully represented in the experiment modeling. Of specific interest is the capsule geometry which controls the channel acoustics, the clad failure mode which effects the interacting masses and fuel/coolant mixing, the fuel condition at failure and the presence of containment gas which determine the initial pressure source, and the heat transfer and phase change modeling which together determine the rate of fuel quenching and the generation of sodium vapor. The methods available in SIMMER and the problems encountered in modeling these features and processes will be exainined.

Geometric Modeling

SIMMER was written primarily for whole core analysis where multi-subassembly sized zones are homogenized and energy exchange occurs between components within a cell rather than between cells. However, in modeling the PBE experiments all of the individual capsule components - fuel, clad, coolant channel, and pressure canister - must be discretely described. For this study the experimental configuration is modeled in a $6 \times 65$ node array as shown in Figure 1l. The model consists of a single fuel pin in a coolant channel below a movable piston. Due to code limitations, failure is assumed to be a full circumferential break with the break height varied parametrically. Radially, there are 3 nodes in the fuel pin and 2 in the coolant channel. The nominal radial mesh width is $1 \mathrm{~mm}$. Axially, the mesh varies from 5 to $20 \mathrm{~mm}$ over the length of the pin. The node boundaries are set to fall within the clad and molybdenum walls. This permits condensation to occur on structure both in the pin and in the coolant channel. The pin support inechanism and other coolant channel area changes are roughly modeled as steel tabs protruding into the sodium. The wire wrap and the fluting on the molybdenum liner are included only as they affect the hydraulic dianeter of the channel. The piston facial area and mass are maintained but its density is reduced to that of sodium to avoid numerical problems in SIMMER as movement occurs. The inner pin volume is fixed throughout the calculation. In the experiment the top of the depleted uranium insulator pellet is held down by a spring which allows $5 \mathrm{~cm}$ of travel. This fixed volume approximation affects the calculation of axial mixing within the pin and the amount of free volume in the system for incondensible gas.

One of the more difficult restrictions in modeling the PBE experiments in SIMMER is the limitation to two dimensions. since the experiments were designed to maximize similitude with a reactor pin rather than to simplify modeling, there are many three-dimensional complications. Three-dimensional features include the fluting of the molybdenum liner, the wire wrap, the sodium fill tubes at the top and bottom of the coolant channel, and the fuel pin supports and other partial channel blockages. These components, which can be only roughly approximated in 


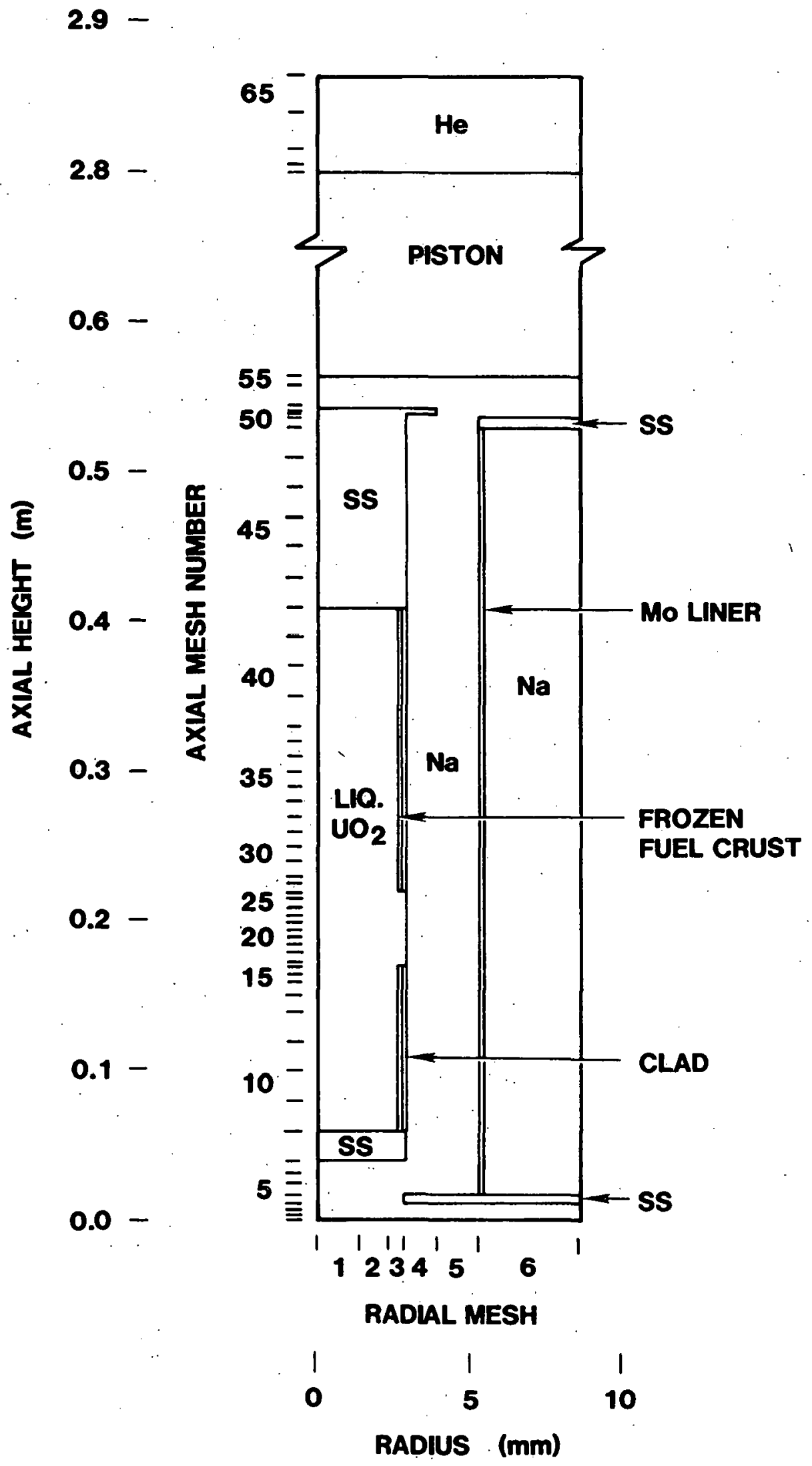

Figure 11. PBE SIMMER Model 
the calculations, can significantly affect the channel flow and mixing. In addition they almost certainly lead to asymmetric pin failure. Furthermore, since the pressure histories at the transducer locations are dominated by the acoustic ringing of the capsule, the increase in effective sodium path length due to the fill tubes is important. However, probably the nost important limitation is modeling the pin break in two dimensions. The break approximation controls the mixing and thermal equilibration within the pin, the nass and thermal condition of the fuel which exits the pin, and the fuel/coolant mixing in the channel. With a large inverted temperature gradient initially in the pin, a full circurnferential break approximation reduces the amount of cooler liquid fuel pushed into the channel and reduces the mixing within the pin. Furthermore, since an axial heating gradient also exists in the pin, the length of the break. is important. In two-dimensions one must choose between setting a break area or the axial extent of the break. Also, with a full circumferential break there is no escape path For sodiun around the pin and fuel/sodium mixing is increased.

Material Properties and Initial Conditions

Since there is no pin model in SIMMER, the analysis starts at the point of pin failure with initial conditions provided by the EXPAND pin-failure code. ${ }^{4}$ The fuel is entirely molten except for a thin refrozen crust on the clad. Individual fuel temperatures are entered for each node in the pin to describe accurately the extent and location of the hottest fuel which drives the experiment. For the nost part temperature independent material properties from the AivL "blue book" Exceptions to this include the sodium critical temperature, assumed to be $2509 \mathrm{~K}$, the conductivity of liquid $\mathrm{UO}_{2}$ and the fuel equation-of-state. A liquid $\mathrm{UO}_{2}$ conductivity of $7 \mathrm{~W} / \mathrm{MK}$ is used based on recent theoretical and experimental work. ${ }^{6}$ Coefficients of the analytical equation-of-state for $\mathrm{UO}_{2}$ in SIMPIER are based on measurements by Reil' which used dosimetry techniques consistent with the PBE experiments. In the area of interest, the fuel vapor curve is so steep that a $7 \%$ increase in temperature doubles the pressure. Because of this sensitivity and the total uncertainty range in the neasured energy deposition in the pin (thought to be about $10 \%$ ), the energy deposition used in the reference calculation has been adjusted to give approximately the correct magnitude on the initial pressure peak. In the base-case calculation, this requires raising the energy deposition 15\% from the measured deposition. The resulting peak fuel temperature is then $4670 \mathrm{~K}$ with a corresponding fuel vapor pressure of $22 \mathrm{MPa}$ in the pin at failure. If the SIMlMR EOS correlations were based on ANL "blue book" data for $\mathrm{UO}_{2}$, the peak temperature would be over $6000 \mathrm{~K}$ and the energy-deposition adjustment would have to be $50 \%$ higher than the nominal measurement. 
The restriction of constant material properties in SIMMER is particularly limiting in the PBE analysis. A constant liquid sodium density precludes single phase pressures as fuel first contacts the sodium. Jacobs ${ }^{8}$ attributes the initial pressure spikes observed in the $\mathrm{PBE}$ carbide experiments to this mechanism. Also, the energy exchange calculations are affected by the constant thermal properties, especially the thermal conductivities which actually change substantially over the range of temperatures encountered in the PBE experiments.

Phenomenological Modeling

Since the mixing and heat transfer occurring in the PBE experiments control many of the pressure generation mechanisms, the models used in SIMMER to calculate these processes will be briefly discussed.

SIMMER has several liquid components but a single liquid field. That is, each liquid component within a node has an individual temperature, but all move with the same velocity. As material moves across a cell boundary, each component ternperature is instantly equilibrated. Other investigators have evaluated this approximation and have found substantial variations in the prediction of work energy with node size.9 As expected, large errors result whenever large temperature gradients exist across node boundaries. The axial node structure used in the PBE model with $.5 \mathrm{~cm}$ nodes near the break is probably adequate. However, the use of only 3 radial nodes in the pin to describe a peak-to-minimurn initial temperature ratio of 1.4 is at best marginal.

As in any Eulerian code, component mixing in SIMMER is overpredicted due to numerical diffusion. In fact, with a single liquid velocity field all liquid/liquid mixing is numerical and to a large extent, predetermined by the node structure. Since. the generation of sodium vapor pressure in the PBE experiments is strongly influenced by the extent of fuel/coolant mixing, the accuracy of SIMMER predictions of this process must be suspect.

Probably the most important energy exchange mechanisms in the PBE analysis is liquid/liquid heat transfer between fuel and sodium. This process provides a means of fuel quenching as well as a source of pressure from sodium vapor. For SIMMER a new model was developed which is currently unverified and uncalibrated by experiment. It is a conduction model where an estimate is made of the droplet collision frequency, contact time and area, and the heat transfer coefficient. only conduction can be considered because the single liquid field velocity precludes a convective calculation. The uncertainty introduced by this approximation is discussed in Reference 9. Furthermore, the generation of vapor films and variations in flow regime is 
not included. Within the SIMMER model the conduction length used to determine the heat transfer coefficient is assurned to be .2 of the droplet radius. For determining this droplet radius the dominant fragmentation mechanism is based on a wever number criteria (using the relative velocity between the liquid and vapor fields) developed from single droplet experiments. A major shortcoming of this model for application to the PBE experiments is that it does not treat a droplet of liquid $\mathrm{UO}_{2}$ impacting a slug of sodium. A Weber number cannot even be calculated for that case in SIMMER. In view of the large uncertainty added by the multicomponent, multiphase flow in the PBE experiments, the liquid/liquid heat transfer rate was varied parametrically in this study by means of an input rultiplier.

A second process which can be important to fuel quenching is the energy exchange between fluids and structure. In SIMMER the rate of this heat transfer is calculated by combining the heat transfer coefficient for each fluid component (both liquid and vapor) with the coefficient for the structure side. The structure coefficient is an input parameter and usually determined assuming a thin shell model. The fluid side coefficient is based on a local Nusselt number correlation of the form:

$$
N u_{m}=C_{m 1} \operatorname{Re}_{m}^{C_{m 2}} \operatorname{Pr}_{\bar{m}}^{C_{\mathrm{m} 3}}+C_{m 4}
$$

where $\mathrm{Re}_{\mathrm{m}}$ and $\mathrm{Pr}_{\mathrm{m}}$ are the local Reynolds and Prandtl numbers, respectively, for fluid component $\mathrm{m}$, and $\mathrm{C}_{\mathrm{ml}}-\mathrm{C}_{\mathrm{m} 4}$ are input constants. This correlation was developed for sinyle phase, fully developed turbulent flow in a pipe and does not account for twophase effects, filins, the presence of multiple components and noncondensible gases, or changes in flow conditions. For the structure side the usual approximation for the heat transfer coefficient is:

$$
\mathrm{h}=\mathrm{K} / \mathrm{X}
$$

where $X$ is the structure half-thickness. For sudden contact at highly different temperatures, the initial effective conduction length can be much less than the material half-thickness due to transient effects. For example, in the PBE experiments with a clad thickness of $.038 \mathrm{~cm}$, the thermal response time (approximated as $x^{2} / \alpha$, where $\alpha$ is the thermal diffusivity of steel) is about $8 \mathrm{~ms}$, much longer than the period of interest in this calculation. This approximation will lead to an underprediction of the rate of heat transfer to structure. 
Phase transformations constitute another dominant energy exchange mechanism. In this study the single component condensation option in SIMMER is used. A more comprehensive luulticomponent model is under development but not yet ready for use on fast transient problems. In the single component rnodel the rate of vaporization or condensation is controlled by the rate of heat conduction to the interface where the place transition is assumed to occur. Phase transitions are permitted at liquid/vapor interfaces of identical components and at fluid/structure interfaces. The model has several important limitations which should be noted: Vapor is not allowed to condense on a different liquid component; e.g., fuel vapor cannot condense on cold liquid sodium. The effects of noncondensible gases, multiple components and multiple phases are not included. Furthermore, homogeneous condensation of vapor is. not modeled at all. This limitation is particularly important in nodes without structure, because in these nodes condensation cannot occur, regardless of the vapor temperature.

Finally, as mentioned earlier SIMMER was developed for whole core analysis where large zones are normally hornogenized and energy exchange occurs primarily between components within a node and not between adjacent nodes. Thus, internodal conductive heat transfer is not modeled and energy exchange between nodes occurs only through mixing. In the PBE model with multiple nodes within the single fuel pins, very large temperature gradients exist between nodes. However, scoping calculations indicate that due to the relatively low conductivity of the oxide fuel and the short period of interest, the error introduced by neglect of internodal heat transfer is small.

In summary, it may be concluded that the energy exchange modeling in SIMMER is simplistic in view of the complexities of the PBE experiments. Therefore, analyses have been performed parametrically to determine and investigate the dominant heat transfer processes. However, biases resulting from the phasechange models and from numerical mixing are present in all of the calculations.

Calculations and Analysis

The analysis performed in this study consists of a parametric evaluation of PBE-5S using SIMMER. An initial reference calculation has been run with all of the heat transfer and phase change models in SIMMER turned on using the geometric model illustrated in Figure 11 with a $5 \mathrm{~cm}$ break approximation and a "best estimate" set of initial conditions. Subsequent calculations examine the effects of changing the initial conditions, the break approximation, material properties, the heat transfer rates and the effect of including incondensible gas in the fuel. The calculational matrix is shown in Table II. The magnitude of the initial pressure peak and the nominal pressure at $3 \mathrm{~ms}$ at the bottom transducer location are also tabulated for each 
TABLE II

Tabulation of SIMMER Calculations of PBE-5S

SIMMER

Case

Number
Case Description
Calculated and Measured
Pressure at botton
Transducer Location
$\begin{aligned} & \text { Initial Nominal } \\
& \text { Peak Pressure }\end{aligned}$
\begin{tabular}{ll} 
(MPa) & at 3 Ma \\
\hline
\end{tabular}

PBE-5S Experiment

1 Reference $-5 \mathrm{~cm}$ Break

2 No Heat Transfer

3 No Sodium Vaporization

4 Viscous shear in Fuel Pin

5 Alternate Fuel EOS

6 Large Initial Temperature Gradient in Fuel.

46

49

40

38

49

40

18

54

11

7 Large Initial Temperature Gradient in Fuel/Alternate Fuel EOS

$81 \mathrm{~cm}$ Break

34

11

27

19

- Large Initial Temperature Gradient in Fuel $/ 10 \mathrm{~cm}$ Break

60

14

10 Large Initial Temperature Gradient in Fuel/ $10 \mathrm{~cm} \mathrm{Break/Low:Fuel-Sodium} \mathrm{Heat} \mathrm{Transfer}$

11 Peak Temp. $=4550 \mathrm{~K} /$ Large Initial Temp. Gradient in Fuel/10 cm Break

58.

16

12 Peak Temp. $=4350 \mathrm{~K} /$ Large Initial Temp. Gradient in Fuel/10 cm Break

13 Peak Temp. $=4350 \mathrm{k} /$ Large Initial Temp. Gradient in Fuel/10 cm Break/Low Fuelsodium lleat Transfer

14 Incondensible Gas/Revised Fuel EOS

15 Incondensible Gas/Revised Fuel EOS/ No Heat Transfer

8

4


calculation and compared with the experimental values. The bottom transducer location is chosen for comparing the pressure histories because it is least affected by the moving piston. The 3 ris pressure is taken to be the average pressure as. 3 ms is approached. In all of the calculations it corresponds very closely to the pressure in the interaction zone at this time. The calculated pressure histories for each case in Table II are presented in Appendix A along with the measured histories for comparison. Calculations for both transducer locations and for node $R, z=4,22$ (see Figure ll) in the sodium channel at the center of the interaction zone are included.

The pressure traces from the reference calculation are shown in Figure $\mathrm{A}-2$. At the bottom transducer location the initial pressure peak of $49 \mathrm{MPa}$ decays to about $16 \mathrm{MPa}$ in $3 \mathrm{~ms}$. This is in contrast to the experiment where a $46 \mathrm{MPa}$ peak decays to $2 \mathrm{MPa}$. A lower initial peak and a more rapid decay is observed at the top of the vessel due to relief from the movable piston. The calculated ratio of top to bottom peak pressures is 1.44 and compares well with the measured value of 1.48. At both transducer locations the pulse frequency is higher than observed experimentally. This misprediction is most probably due to geometric modeling approximations for the pressure vessel. In sensitivity studies on model changes, it has been observed that the inclusion of the sodium fill tubes located at the top and bottom of the vessel significantly decreases the frequency in the pressure train by increasing the effective sodium path length.

During the early part of the calculation, the pressure within the interaction zone increases to about $30 \mathrm{MPa}$ as fuel and sodium mix in the channel and as sodium is driven into the fuel pin. Sodium moves into the pin beginning as early as $.05 \mathrm{~ms}$. At .1 ms a small two-phase zone exists in the inner channel and inside the pin. Furthermore, several of the nodes within the pin contain over $10 \%$ by volume liquid sodium. By .3 - .4 ms the returning pressure waves reflected of of the channel ends have collapsed almost all of the two-phase region in the channel and have forced more liquid sodium into the pin. At $.6 \mathrm{~ms}$ the interaction zone begins to expand ayain and the pressure begins a slow decay. The two-phase zone extends over the fuel break height in the inner channel after $1 \mathrm{~ms}$ and is expanding upward and out. By $2 \mathrm{~ms}$ the full channel from the bottom of the break to $3 \mathrm{~cm}$ above the break is predominantly vapor filled. The two-phase zone is $17 \mathrm{~cm}$ long after $3 \mathrm{~ms}$, and the pressure has decayed to about 16-18 $\mathrm{MPa}$.

Inside the pin and in the channel immediately outside of the break, SIMMER does not predict any significant decay of the pressure. As the fuel temperature in the pin equilibrates through mixing, additional nuclear heating from the tail of the pulse maintains approximately the same peak temperature and hence the same fuel vapor pressure. In fact, at $3 \mathrm{~ms}$ the 
midplane fuel temperature across the pin is a uniform $4550 \mathrm{~K}$ to within $50 \mathrm{~K}$. In contrast, at the start of the calculation this midplane temperature varies from $3800 \mathrm{~K}$ at the centerline to $4700 \mathrm{~K}$ at the outer pin radius with an average of $4220 \mathrm{~K}$. In the first $3 \mathrm{~ms}$ the average inidplane temperature has increased over $300 \mathrm{~K}$ despite radial and axial mixing within the pin and heat transfer to the clad and coolant. The overall averaye fuel temperature increases from $3890 \mathrm{~K}$ to $4320 \mathrm{~K}$ in this time period. In addition, fuel in the channel heats a significant amount of liquid sodium to very high temperatures. At $3 \mathrm{~ms}$ the temperature of the liquid sodium in the interaction zone varies between $2150 \mathrm{~K}$ and $2200 \mathrm{~K}$. The corresponding sodium vapor pressure is $15 \mathrm{MPa}$. This, even if the fuel vapor source dissipated, the pressure would be sustained by sodium vapor.

The character of the measured pressure traces first seemed to indicate fuel vapor as the most likely driving pressure. However, the dilemma with this explanation is that if the peak fuel temperature at failure corresponds to a Fuel vapor pressure of approximately half of the observed initial pressure peak (assuming acoustic effects will double it), the equilibrium temperature yields too high a vapor pressure at late tines. There are many possible explanations: the initial temperature distribution within the pin may be more peaked than predicted by EXPAND, the break approximation which affects intra-pin mixing may be poor, or uniodeled rate effects nay exist in the fuel EOS resulting in high transient vapor pressure. These hypotheses also require substantially less heat transfer to the sodiun than predicted by SIMMER to prevent the generation of a sustained sodium vapor pressure. This is not surprising as it is probable that the nominal SIMMER model overpredicts mixing and the liquid/ liquid heat transfer as discussed earlier.

In the reference calculation, the clad temperature is initially assuned to be a uniform $1000 \mathrm{~K}$ and the nolybdenum liner $770 \mathrm{~K}$. A portion of the clad is modeled within the outer fuel node and the remainder within the coolant channel to allow condensation on structure on both sides. At $3 \mathrm{~ms}$, the inner clad is intact, but $2 \mathrm{~cm}$ of the clad in the channel above the break has melted off. This is due to the higher velocities and hence higher heat transfer rates in the channel. It appears that the full clad will begin to melt after about 6 ms. Outside of the break a single node of the molybdenum liner is at melt after $3 \mathrm{~ms}$. In the experiment no evidence of melting of the inolybdenum liner was observed in the post irradiation examination.

As the interaction zone expands, the droplet radius for liquid fuel varies from $50-250 \mathrm{\mu m}$. In the posttest disassembly of several of the $\mathrm{PBE}$ experiments the mass mean fuel particle size (nominally the diameter) was found to be $130 \mu \mathrm{m}$. However, there is no information on the fuel actually involved during the early part of the transient. The calculated amount 
of fuel in the channel is presented in Figure 12. Again, in the absence of fuel motion diagnostics there is no measurement for comparison.

A time plot of the calculated pressure in the inner portion of the coolant channel for the first 2 ms after clad failure is shown in Figure 13. The fuel pin extends from 6 to $41 \mathrm{~cm}$ and the break is centered at $19.5 \mathrm{~cm}$. The pressure source in the interaction zone is the fuel vapor pressure enhanced by sodium vaporization. The pressure waves propagate to the channel ends and then reflect off the ends and off the two-phase interaction zone. Essentially, the fiyure illustrates the channel acoustics as the pressure train rings down.

This picture portrays the problem inherent to the pin geometry experiments. Pressure measurements, the principal experimental diagnostic, are performed at the top and bottom of the coolant channel. However, it is the interaction zone behavior which is of specific interest. SIMMER is used. to calculate the details within this interaction zone as well as the system response at the transducer locations. Comparisons are made of the calculated and measured pressure histories at these transducer locations to indicate successful modeling of the dominant processes. However, there is no assurance of a unique solution.

For the first variation on the reference SIMMER calculation, Case 2 in Table II, all heat transfer is turned off. The only pressure source is fuel vapor and the only energy exchange is convective mixing of the fuel and continued neutronic heating. This case has been run in order to look at the acoustic ringing of the channel and to isolate and maximize the fuel vapor pressure. The calculated pressure traces are shown in Figure A-3. At the bottom transducer location the expected doubling of the initial pressure source from acoustic effects occurs followed by a slow ringing down. The $40 \mathrm{MPa}$ peak is $9 \mathrm{MPa}$ lower than the peak in the reference calculation while the pressure at $3 \mathrm{~ms}$ is $4 \mathrm{MPa}$ higher. This comparison with Case 1 indicates the contribution of sodium vapor pressure and the early quenching of fuel on liquid sodium and structure, as calculated in the reference case.

In Case 3 nominal heat transfer is modeled but sodium vaporization is suppressed. The resulting pressure traces are shown in Figure A-4. This calculation provides an upper bound on the rate of pressure decay for the given model and initial conditions. The pressure source is entirely from fuel vapor with a maximum quenching of fuel by liquid sodium. A comparison with Case 1 isolates the pressure contribution of sodium vapor to the initial pressure peak and its inhibiting effect on fuel quenching. It appears that sodium vapor increases the initial pressure by $11 \mathrm{MPa}$ and the $3 \mathrm{~ms}$ pressure by $1 \mathrm{MPa}$. Cases 2 (with no heat transfer) and 3 bound the rate of fuel quenching. 


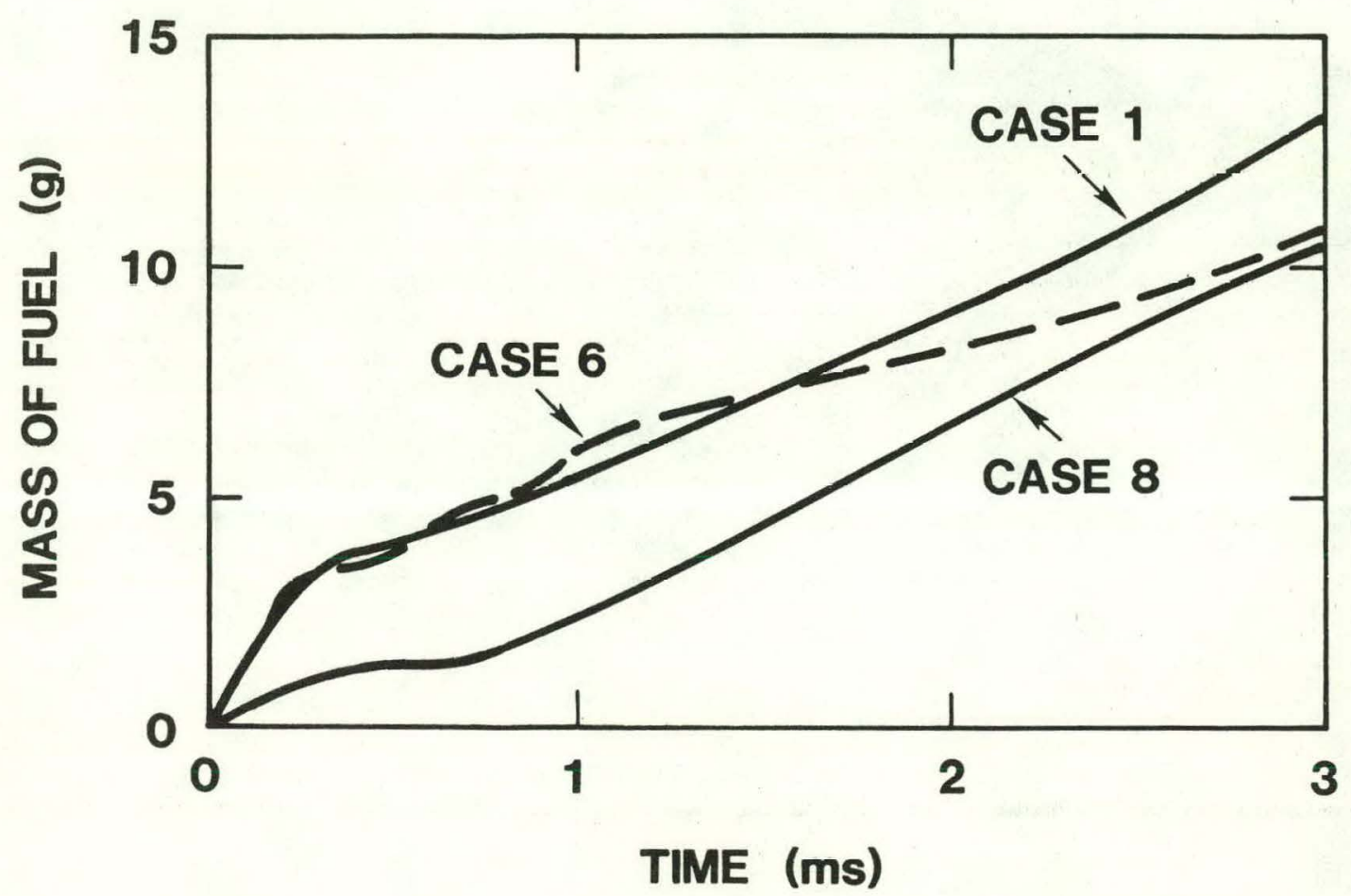

Figure 12. Calculated Mass of Fuel in Sodium Channel 


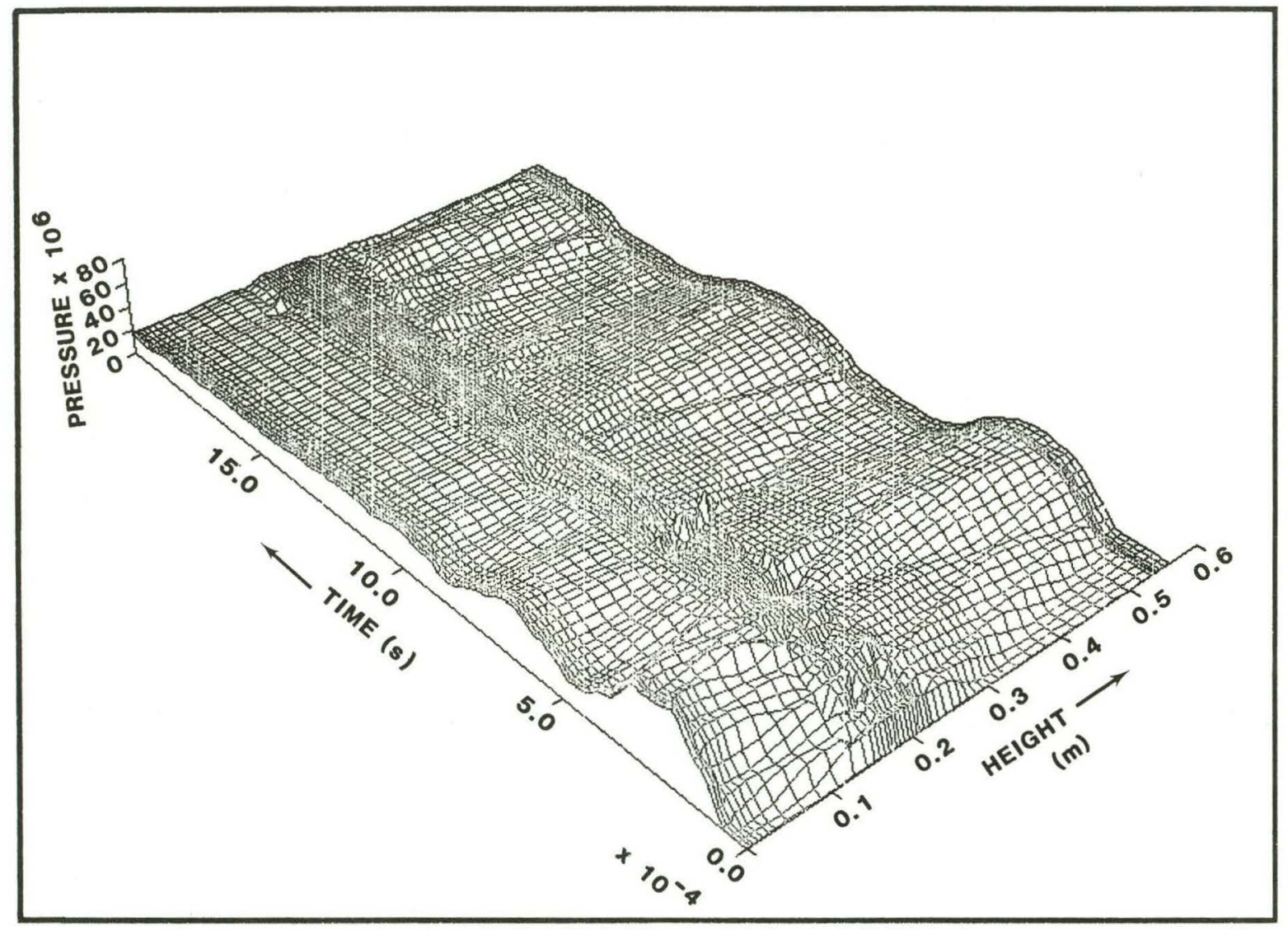

Figure 13. Calculated Pressure History in Sodium Channel 
It is observed in the pressure histories from these two calculations that fuel quenching lowers the initial peak by $2 \mathrm{MPa}$ and the $3 \mathrm{~ms}$ pressure by $5 \mathrm{MPa}$. It is concluded from this calculation that even with maximum quenching, the pressure source from fuel alone is too high.

The effect of viscous. shear in the fuel pin is examined in case 4 using an option in SIMMER which includes drag between adjacent cells under laminar flow conditions. In the reference calculation there is no coupling between adjacent liquid cells. The objective is to investigate the possibility of enhanced mixing within the pin, which would thus speed the temperature equilibration. Although the details of the pressure histories, as seen in Figure A-5, vary from Case 1, the envelope is the same. Also, from temperature histories it appears that the rate of equilibration within the pin is about the sane in the two calculations. It is concluded that viscous shear does not significantly affect the calculation.

Since heat transfer rates depend on relative temperatures, the fuel equation-of-state affects the calculated pressure trace even though the initial source pressures are normalized. As mentioned earlier, the coefficients for SIMMER's analytical EOS in the reference calculations are based on data by Reil. This data was chosen because the dosimetry techniques were similar to those used in the PBE experiments so that any systematic errors should cancel. However, these measurements indicate much lower temperatures for a given pressure than would be obtained from the more widely used ANL EOS. To investigate the effects of varying the fuel EOS, Case 5 has been run using the ohse values for UO $_{2}$ vapor pressure. These values lay about midway between the Reil data and the recommended AivL "blue book" values. The peak temperature in Case 5, corresponding to $22 \mathrm{MPa}$, is $5180 \mathrm{~K}$ vs. $4670 \mathrm{~K}$ in Case 1.

The pressure traces obtained from the hotter initial fuel temperatures of Case 5 are shown in Figure A-6. A lower initial peak pressure is calculated with large undamped oscillations. From Case 3 one expects that fuel vapor alone contributes $40 \mathrm{MPa}$ to the initial pressure peak. It is curious that in this calculation with its higher implied heat transfer rates, the initial pressure peak is also $40 \mathrm{MPa}$. Irdeed, the calculated pressure trace looks much like the one obtained in Case 2 with no heat transfer. The apparent reason for this low initial pressure peak is that in Case 5 there is no early sodium entry into the pin. In the reference calculation liquid sodium is forced into the pin as early as .05 ras. In case 5 with hotter fuel there is a longer delay in sodium entry which results in the absence of any significant contribution from sodium vapor to the initial pressure. However, the higher pressure at $3 \mathrm{~ms}$ indicates that more heat is ultimately transferred to sodium in Case 5 . This sensitivity to the presence of sodiur in the pin, increases the importance of uncertainties in the initial rip description. 
The slow pressure decay observed in Case 3 indicates that even with maximum quenching the pressure source from fuel vapor is too high. One way to maintain the initial pressure, but to obtain a more rapid decay is to increase the initial temperature gradient in the fuel. In the reference calculation the initial conditions are established using the EXPAND pin failure code which provides heat transfer calculations through the point of pin failure. If this pre-failure heat transfer is overpredicted or if the energy deposition peaking is underpredicted, a slower pressure decay would result. The effect of increasing the gradients in the initial temperature distribution was bounded in Case 6 by using the energy deposition profile for the fuel temperature rather than the calculated profile at failure. The same peak temperature of $4670 \mathrm{~K}$ is used to provide an identical initial pressure source but the average fuel temperature within the pin decreased from $3890 \mathrm{~K}$ to $3450 \mathrm{~K}$. The calculated pressure histories are shown in Figure A-7. The increased temperature gradient results in a higher initial pressure peak, indicating a larger contribution from sodium vapor, and a more rapid decay, down to $11 \mathrm{MPa}$ at $3 \mathrm{~ms}$. The calculation has been extended to $5 \mathrm{~ms}$ to see if this rapid decay would continue. In the additional $2 \mathrm{~ms}$ the calculated pressure at the bottom transducer location decreased only $1 \mathrm{MPa}$ to $10 \mathrm{MPa}$.

In Case 6 the peak fuel temperatures in the pin decrease more rapidly than in the reference calculation, as expected. The amount of fuel in the channel initially tracks case 1 as seen in Figure 12, but falls off with the lower fuel vapor pressure within the pin. The sodium temperatures in the interaction zone follow a similar pattern. For the first $2 \mathrm{~ms}$ the liquid sodium temperature histories are similar. Then the Case 6 temperatures decrease more rapidly due to the reduced rate of fuel entering the channel. Also, with less fuel motion there is less mixing in the pin, and at $3 \mathrm{~ms}$ a large radial temperature gradient still exists. By $5 \mathrm{~ms}$ the fuel is well equilibrated with a peak temperature of about $4300 \mathrm{~K}$, corresponding to about $9 \mathrm{MPa}$ of fuel vapor pressure. The amount of hot liquid sodium is much less than in Case 1, but the peak temperatures are still over $2000 \mathrm{~K}$.

The pressure outside the break in Case 6 is artificially high because there is no structure on which fuel can condense. This problem is apparent in all of the calculations but it is more significant here because the pressure in the channel relative to the pin pressure is higher in this case. As discussed earlier, SIMMER has no model for homogeneous condensation. Phase changes are permitted only at liquid/vapor interfaces of identical components and at fluid/structure interfaces. This approximation causes special problems in the PBE analysis where there is no structure around the break. The fuel is hot and vaporizing, but the vapor temperature can be low due to heat transfer with the cold sodium. With no structure for fuel condensation, the pressure in these nodes is artificially high. 
In fact, some nodes contain vapor several hundred degrees below the fuel saturation temperature. Furthermore, as the calculation proceeds and the outer clad erodes, the affected reyion grows.

The next variation, case 7 , combines the larger initial temperature gradients of Case 6 with the alternate fuel EOS used in Case 5. As shown in Figure $A-8$, the resulting pressure traces exhibit the same large oscillations observed in case 5 and the rapid pressure decay of Case 6 . The secondary peak pressure spikes result from numerical problems in the solution. They are due to local, single-phase overpressures in the interaction zone which ring up and down the channel.

Case 8 starts an investigation of the break approximation. With no experimental data on the extent or location of the break, its modeling is somewhat arbitrary. Pin failure is expected to occur at the location of peak power, but its extent is completely unknown. If failure is due to thermal stress, a local failure is not a mitigating effect and one would expect an extensive break. Since the axial energy depositon curve is fairly flat over the central $10 \mathrm{~cm}$ of the pin, a break could extend over this length. However, if internal pressure is a significant contributor to failure, a local failure would relieve the stress. In the reference calculation a break length of $5 \mathrm{~cm}$ has been selected. A smaller break should reduce the mixing both within the pin and in the channel. This is investigated in case 8 by reducing the break size to $1 \mathrm{~cm}$. This small break assumption appears to affect many aspects of this calculation. There is no sodiun entry into the pin, even at late times. The sodium heating in the channel is very localized, but the peak temperatures are similar to Case 1 . The smaller break restricts early motion of the fuel into the channel as seen in Figure 12. At 3 ms the peak fuel temperatures are about $100 \mathrm{~K}$ higher than in the reference calculation and about equal to the initial peak temperatures. Fuel vapor pressure dominates the entire calculation with little decay. The resulting pressure histories are shown in Figure A-9. At the bottom transducer location the pressure oscillates about $19 \mathrm{MPa}$ with no obvious decay. In the interaction zone a slower pressurization occurs, similar to that in case 5. This behavior may be somewhat influenced by the node structure around the break. The same model has been used as in the reference calculation, so the break is spanned by only two axial nodes. Model sensitivity studies have not been. run and the effect of this approximation is uncertain.

A large break should promote fuel equilibration and mixing with sodium and thus enhance the decay of the fuel vapor pressure source. In case 9 a $10 \mathrm{~cm}$ break approximation is combined with the large initial temperature gradient of case $\sigma$ in an attempt to maximize the pressure decay. As can be seen in Figure $A-10$, this combination provided the highest initial 
pressure peak, $60 \mathrm{MPa}$, with a steady decay to $14 \mathrm{MPa}$ at $3 \mathrm{~ms}$. The calculation has been extended to $5 \mathrm{~ms}$ and the pressure drops to $9 \mathrm{MPa}$.

The effect of increasing the break size can be isolated by a comparison with case 6 . The higher initial pressure indicates a larger sodiurn vapor contribution, which is expected. The nidplane fuel temperatures are well equilibrated by $3 \mathrm{~ms}$ at $4200 \mathrm{~K}$, about $100 \mathrm{~K}$ less than in Case 6 . However, the peak liquid sodium temperatures are higher, between $2100 \mathrm{~K}$ and $2150 \mathrm{~K}$, at $3 \mathrm{~ms}$ and the pressure is being driven by sodium vapor. This explains the slower initial pressure decay compared with case 6 . By $5 \mathrm{~ms}$ the peak sodium temperatures have cooled to about $2000 \mathrm{~K}$ but the fuel temperature has actually increased slightly. This is the first case for which sodium vapor is clearly dominating the calculation. In all of the other cases, except for case 6 for which the fuel and sodium pressure sources appear to be nearly balanced, fuel vapor is always the driving pressure source. This calculation illustrates the dileruma in the PBE analysis. The heat must be rapidly removed from the fuel in order to match the measured pressure decay, however, if this heat is dumped to the coolant it just creates an alternate pressure source with no increased decay.

A subsequent calculation has been run to determine if the sustained pressure observed in case 9 after 2 ms could be reduced by reducing the heat transfer to sodium. Case 10 is identical to Case 9 except that a heat transfer multiplier of . 2 is used for liquid fuel/liquid sodium heat transfer. The initial peak pressure decreases from $60 \mathrm{MPa}$ to $47 \mathrm{MPa}$, reflecting a lower initial sodium vapor contribution, but the pressure at $3 \mathrm{~ms}$ is essentially the same. Again, the difficulty of improving the pressure decay is observed.

A set of 3 calculations has been run with lower initial peak fuel temperatures. The objective of these was to obtain lower fuel vapor pressure at $3 \mathrm{~ms}$, anticipating that sodium vapor would provide increased early pressure. A $10 \mathrm{~cm}$ break is assumed in these cases to allow early mixing of the fuel and sodium in an attempt to match the neasured initial pressure peak with rapidly generated sodium vapor. Case 11 has an initial peak fuel temperature of $4550 \mathrm{~K}$ and a corresponding fuel vapor pressure of $16 \mathrm{MPa}$ while Case 12 has a peak fuel temperature of $4350 \mathrm{~K}$ and fuel vapor pressure of $10 \mathrm{MPa}$. A large initial temperature gradient in the pin is assumed in both calculations. Thus, the effect of the lower peak fuel temperatures can be isolated by a comparison with Case 9 . The peak and average temperature values for the various cases are summarized in Table III. Case 13, the final variation is identical to case 12 except that a multiplier of 0.5 is used in the liquid fuel to liquid sodium heat transfer correlation. 
With the reduced fuel vapor pressure source and the large break, many numerical problems are encountered. In all 3 calculations single-phase overpressures result in large pressure spikes. The stability in SIMMER can be improved by "walking through" the problem periods with very small time steps. However, this has not been done because the pressure decay, which can be obtained from the interaction zone, is of primary interest. Channel ringing from pressure spikes distorts the pressure behavior at the transducer locations, but the interaction zone which is two-phase and highly dispersive, is less affected. Attempts to run calculations with these lower initial temperatures combined with a small break approximation results in such severe numerical problems that they will not run even with much reduced time steps.

\section{TABLE III}

Peak and Average Initial Fuel Temperatures in SIMMER Calculations

SIMMER

Case

Number
Case Description

1 Reference - $5 \mathrm{~cm}$ Break

5 Alternate Fuel EOS

6

Large Initial Temperature Gradient in Fuel

11

$$
\begin{aligned}
& \text { Peak Temp }=4550 \mathrm{~K} / \text { Large } \\
& \text { Initial Temp Gradient } \\
& \text { in Fuel } / 10 \mathrm{~cm} \text { Break }
\end{aligned}
$$

$\begin{array}{lll}\text { Peak } & \text { Average } & \text { Initial } \\ \text { Initial } & \text { Initial } & \text { Fuel Vapor } \\ \text { Fuel } & \text { Fuel } & \text { Pressure } \\ \text { Temp(K) } & \text { Temp(K) } & \text { (MPa) }\end{array}$

4690

3890

22

5180

4290

22

4690

3450

22

4550

3350

16

4350

3200

10

Initial Ternp Gradient

in Fuel/10 cm Break

The pressure histories for Cases 11-1.3 are shown in Figures $A-12-A-14$, respectively. Again, the numerically induced pressure spikes may be neglected because it is the decay in the interaction zone that is important. The $3 \mathrm{~ms}$ pressures for Cases 11 and 12 are equal to or greater than calculated for Case 9. Case 13 has a lower $3 \mathrm{~ms}$ pressure of $9 \mathrm{MPa}$ but the Initial pressure peak is only about half that observed experimentally. This calculation when extended to $5 \mathrm{~ms}$ shows a 
pressure decrease to $5 \mathrm{MPa}$. In Cases 11 and 12 the sodium vapor pressure dominates, whereas in Case 13 both the fuel vapor and sodium vapor pressure sources are approximately equal. Overall, lowering the fuel temperatures and enhancing the sodium vapor generation does little to improve the predictions.

Despite all of these variations, the measured pressure history could not be successfully duplicated. Neither fuel vapor or sodium vapor, alone or in combination, provides the correct behavior. It is apparent that some other pressure source exists. Recent development work on inpile EOS experiments has identified contaminant gases, particularly those resulting from fuel fabrication, as possible sources of very large pressures in "constant" volume experiments. 10 Indeed, the presence of incondensable gases may explain the large differences observed between closed-system and open-system fuel EOS data. In a final pair of SIMMER calculations, an assumed gas concentration of $10 \mu \mathrm{mol}$ per gram of fuel provides an initial internal pressure of $30 \mathrm{MPa}$. This concentration is consistent with levels found in similar fuels as described in Reference 10. Using a fuel EOS which yields less than 2 MPa of initial fuel vapor pressure (the recommended correlation from Reference 5 , the ANL "blue book") the driving pressure at failure is entirely incondensable gas. The pressure traces from Case 14, presented in Figure A-15, show an initial pressure peak of $33 \mathrm{MPa}$ and a very slow decay. Using the nominal heat transfer correlations in SIMMER, sodium vapor is generated and sustains the pressure. In the final calculation, Case 15, heat transfer to the sodium is retarded. The results are shown in Figure A-16. The pressure at the bottom transducer location decays to $5 \mathrm{MPa}$ in $3 \mathrm{~ms}$. This pressure would be further reduced by modeling the axial expansion within the fuel pin (movement of the top insulator pellet) which approximately doubles the free volume in the system in the first $3 \mathrm{~ms}$ after pin failure.

\section{CONCLUSIONS}

The use of SIMMER-II for analyses of small, but integral, disassembly-phase experiments has been exhibited herein by an extensive analysis of the Sandia National. Laboratories' prompt Burst Energetics (PBE) experiment, PBE-5S. Because the diägnos$\bar{t}$ ics of such in-pile experiments are of necessity limited, it is necessary to resort to complicated, multi-dimensional hydrocodes, to extract detailed phenomenology from the experiments. Unfortunately, SIMMER-II, even though one of the most powerful such tools, has enough modeling uncertainties - - e.g., exchange coefficients, phase change rates, Eulerian mesh-cell diffusion -and outright oversimplifications -- e.g., two-dimensional geometry, temperature-independent properties, neglect of important condensation processes, and neglect of liquid-liquid slip -that detailed and unique experiment analysis is probably impossible. 
For very much the same reasons -- i.e., code uncertainties and simplifications combined with less-than-ideal experinent diagnostics -- use of the PBE experiments for SIMHER model verification is probably futile. The hydrodynamics models in SIMMER-II have been shown herein to provide a reasonable nodel for channel hydrodynamics in PBE-5S. However, these models have been quite well examined by previous experiment analysis.ll The heat transfer models in SIMMER are the least well-founded and least-tested in the code. This is an area in which it was hoped some amelioration of the situation would be forthcoming through PBE analysis. Unfortunately, for the reasons detailed above, this has not proven successful.

On this latter point, it is worth noting that the inadequate PBE diagnostics arc only a small portion of the problem. The liquid-liquid heat transfer nodels in SIMMP are of necessity parametric in nature. That is, because all.liquids in a given cell are treated as a single hydrodynamic fluid, the physics of liquid-liquid regines -- relative velocities and the development of inter-phase surface area -- is completely absent. Thus, this aspect of the code cannot be "verified" by any reasonable number of phenomenological experiments.

Nonetheless, PBE analysis does show very clearly that SIMMER analysis should rely mainly on two types of experiments:

(i) highly instrumented simple experiments of those single phenomenologies which are treated physically by SIMMER; and

(ii) large-scale integral experiments of a very prototypic character which serve for parameter adjustment in renaining SIMMER models as well as overall code "proof" tests.

On an upbeac note, the apparent reliability of SIMMER hydrodynamics and overall energy balances has proven useful in delineating the pressure contributions in PBE-5S. In particular, the difficulty in damping out hydrodynamic pressures in the SIMMER model for PBE-5S when high initial fuel vapor pressures were assumed has led to a close examination of the hypothesis that fincondensable ("make-up" or contaminant) gases are a dominant contribution to the apparent $\mathrm{UO}_{2}$ EOS (as seen in closed volume experiments) in the range near the normal boiling point. The relative success of this modeling assumption in reproducing the $\mathrm{PBE}$ pressure decays is a strong corroboration of the hypothesis. 


\section{References}

1. K. O. Reil, M. F. Young, Prompt Burst Energetics Experiments: Fresh Oxide/Sodium Series, SAND78-1561, NUREG/CR0367 (Albuquerque, NM: Sandia National Laboratories, August 1978).

2. L. L. Smith, SIMMER-II: A Computer Program for LMFBR Disrupted Core Analysis, LA-7515-M, NUREG/CR-0453 (LOS Alamos, NM: Los Alamos Scientific Laboratory, October 1978).

3. K. O. Reil, personal communication (1980).

4. M. F. Young, EXPAND: A Pin Failure Analysis Model for Fresh Fuel Pins, SAND81-0836 (Albuquerque, NM: Sandia National Laboratories, July 1981).

5. Properties for LMFBR Safety Analysis, ANL-CEN-RSD-76-1, (Argonne, Il: Argonne National Laboratory, 1976).

6. P. Browning, on the Relative Importance of the Electronic and Radiative Contributions to the Thermal Conductivity of Uranium Dioxide, AERE-M-3034, (Harwell, Oxfordshire, England, United Kingdom Atomic Energy Authority, Atomic Energy Research Establishment, November 1979).

7. K. O. Reil, A. W. Cronenberg, "Effective Equation-of-State Measurements of Uranium Dioxide," Trans An Nucl Soc, 27, 576,1977 .

8. H. Jacobs, M. F. Young, K. O. Reil, "Fuel-Coolant Interaction - Phenomena Under Prompt Burst Conditions," Proceeding of the International Meeting on Fast Reactor Safety Technology, Seattle, WA, August 12-23, 1979, p. 1520 .

9. R. J. Henninger, R. E. Alcouffe, Disassembly Phase Energetics: An Examination of the Impact of SIMMER Models and Assumptions, LA-7998-ms, NUREG/CR-1027 (LOs Alamos, NM: Los Alamos Scientific Laboratory, September 1979.)

10. W. M. Breitung, Contamination Control in Sandia Equationof-State Experiments, SAND80-1277, NUREG/CR-1510 (Albuquerque, NM: Sandia National Laboratories, October 1980.)

11. L. L. Smith, "The SIMMER-II Code and Its Applications," Proceedings of the International Meeting on Fast Reactor Safety Technology, Seattle, WA, August 19-23, 1979, p. 187 . 
Appendix A

Measured and Calculated Pressure Histories

$$
\text { A- } 1
$$


TOP TRANSDUCER LOCATION

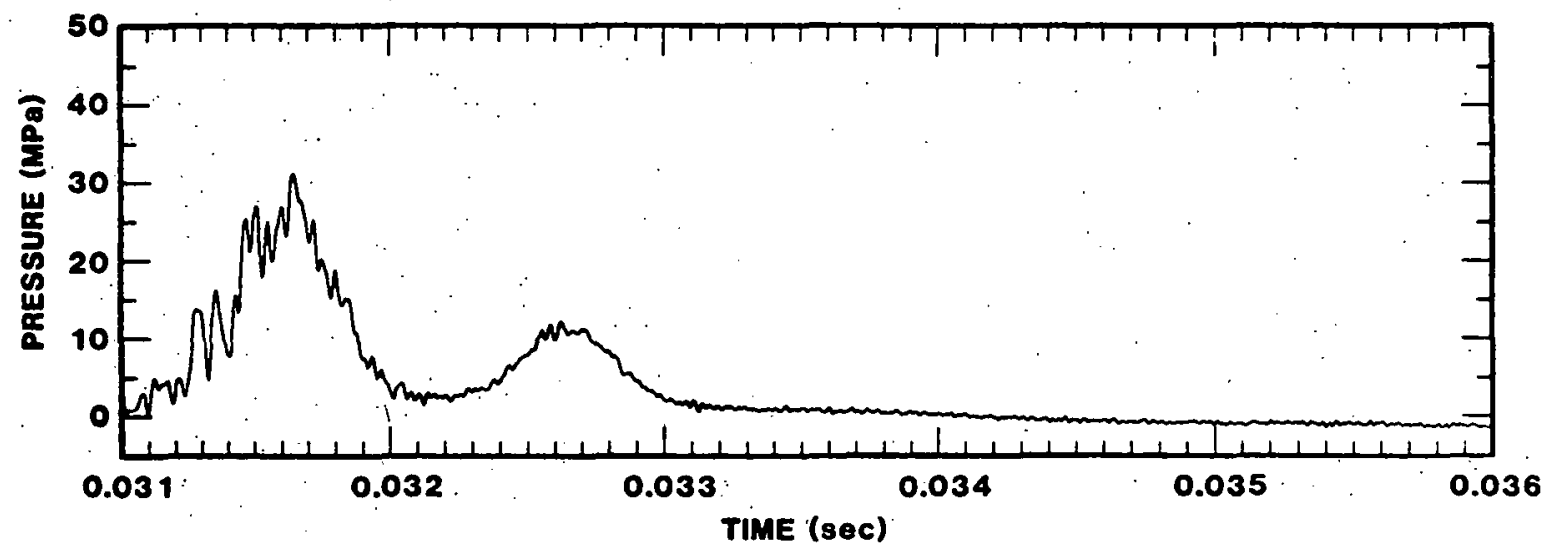

TIME (sec)

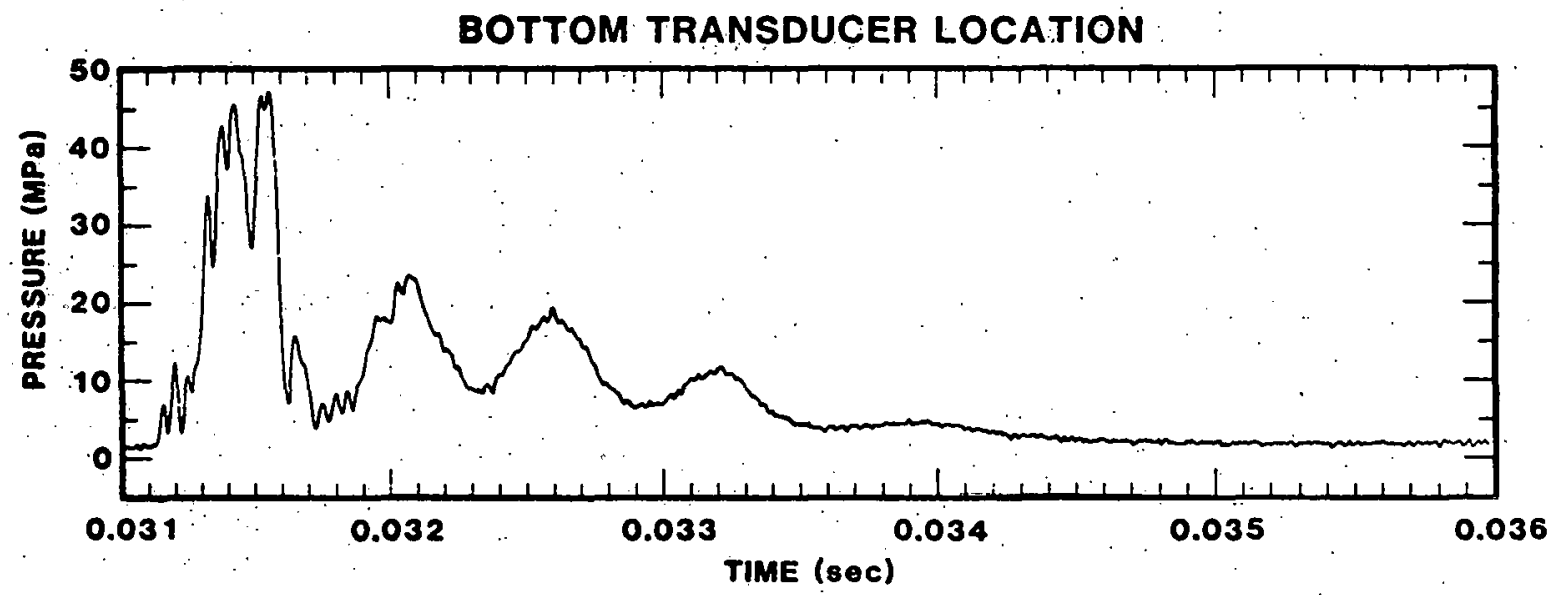

Flgure A-1. PBE-5S Measured Pressure Histories 

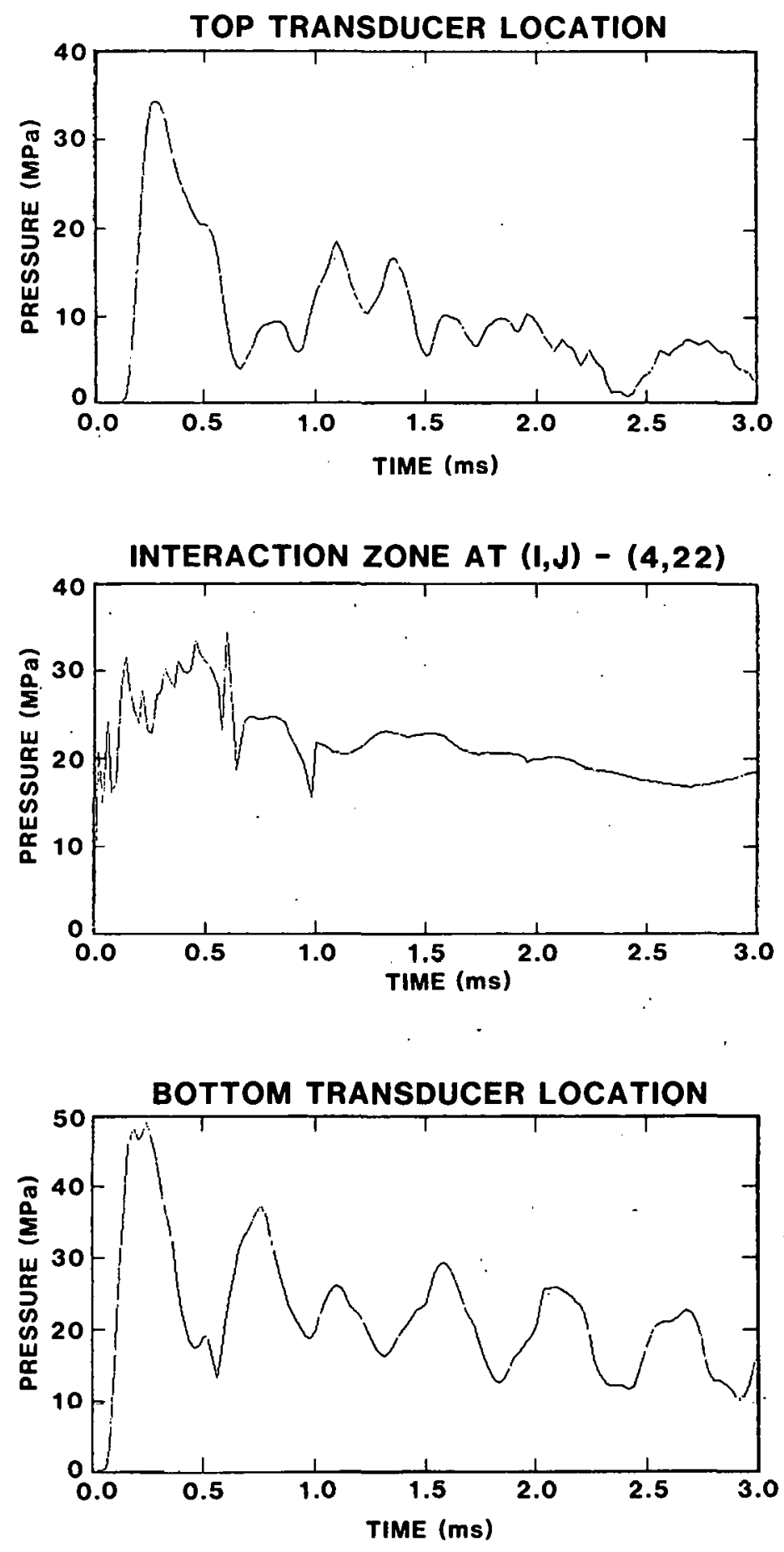

Figure A-2. Calculated Pressure Histories - Case 1 

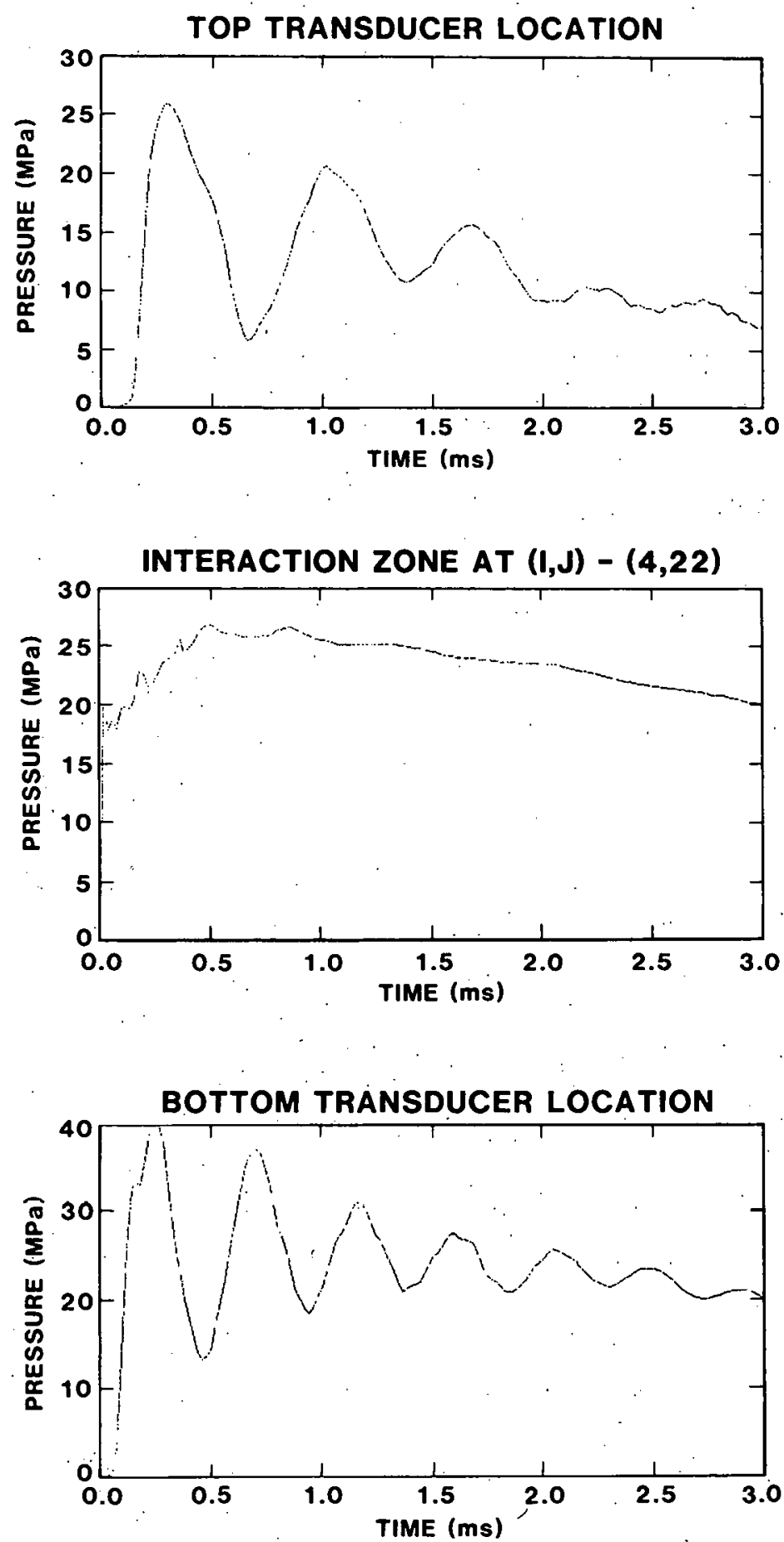

Figure A-3. Calculated Pressure Histories - Case 2 

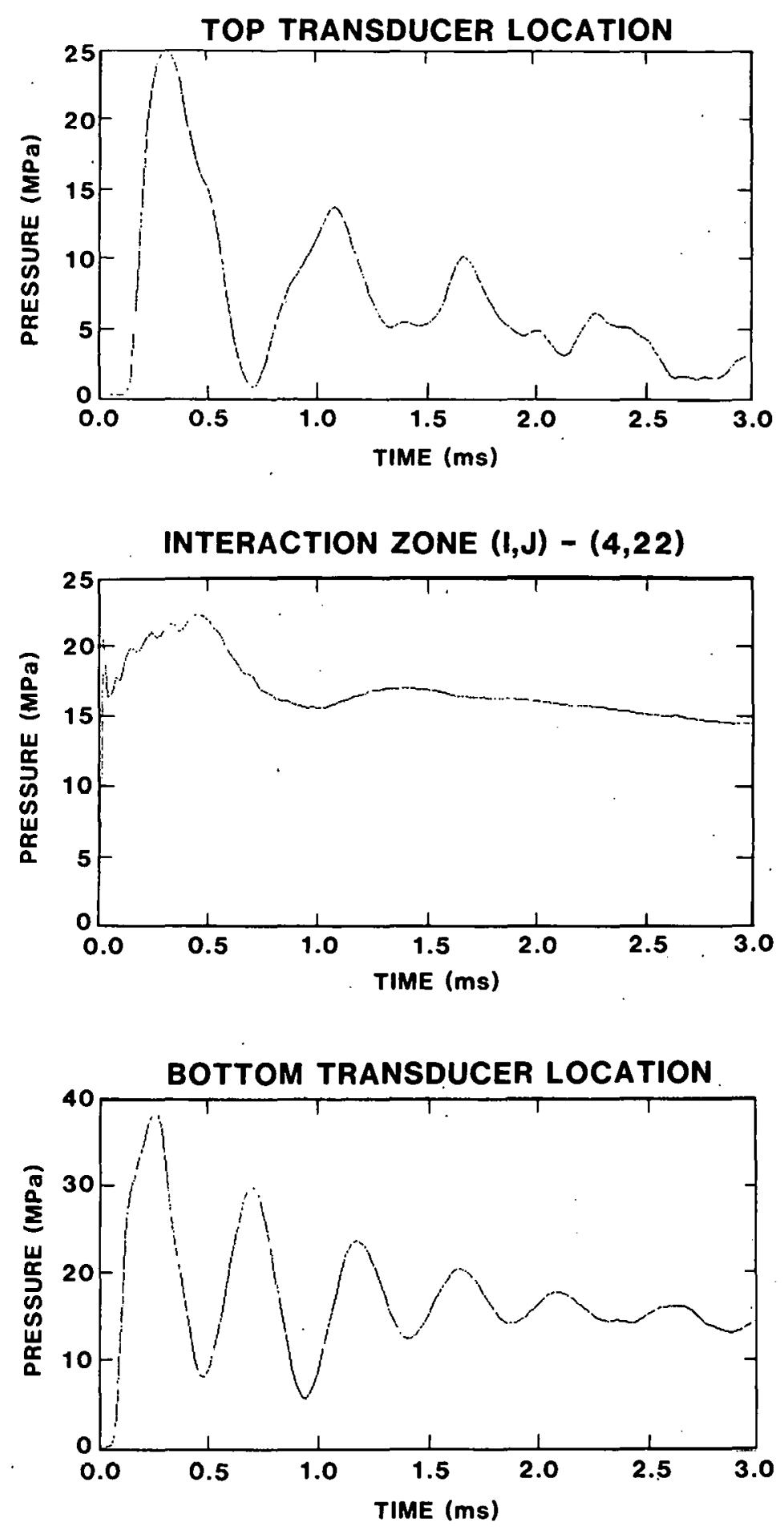

Figure A-4. Calculated Pressure Histories - Case 3 

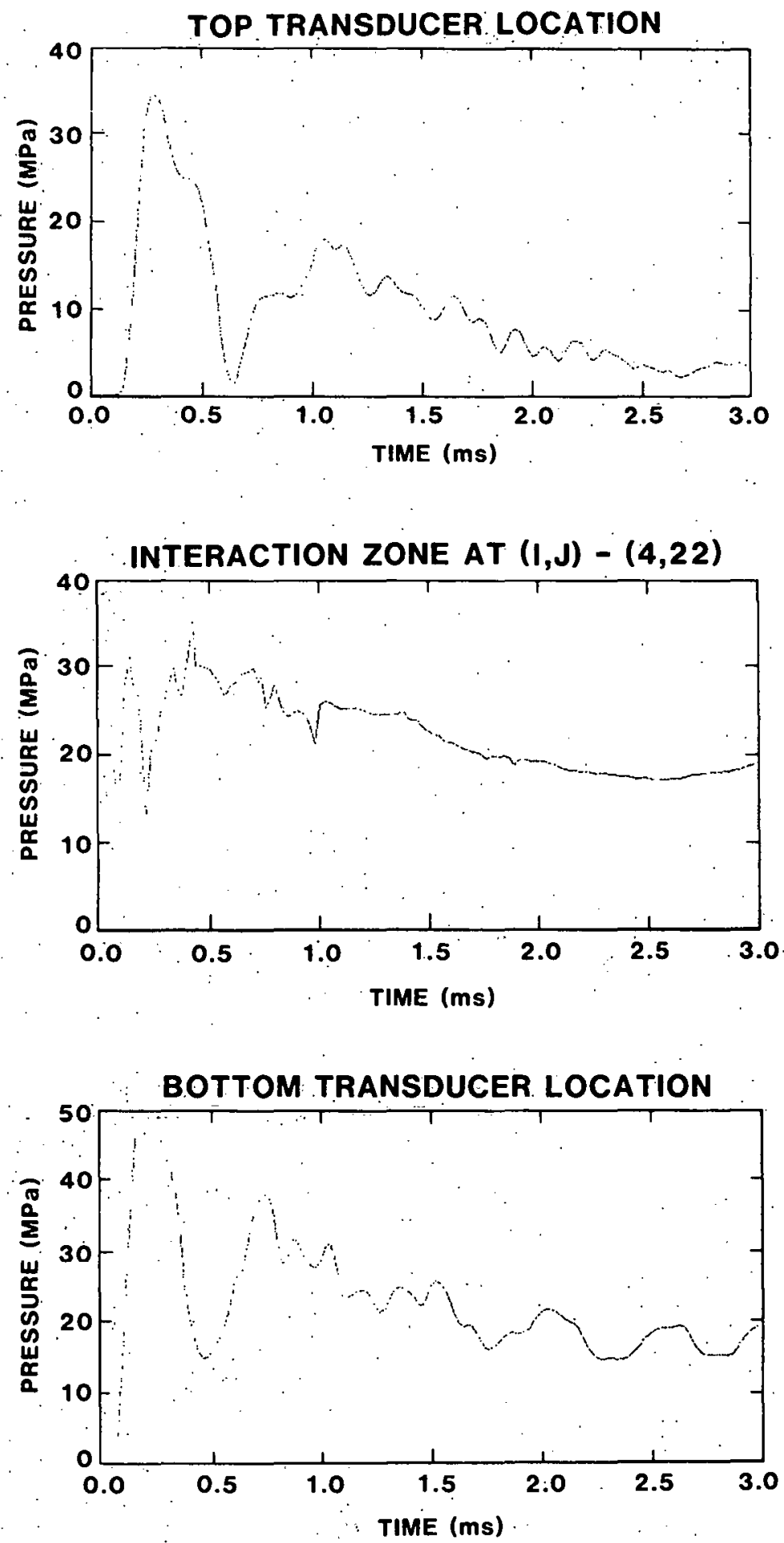

Figure A-5. Calculated Pressure Histories - Case 4 

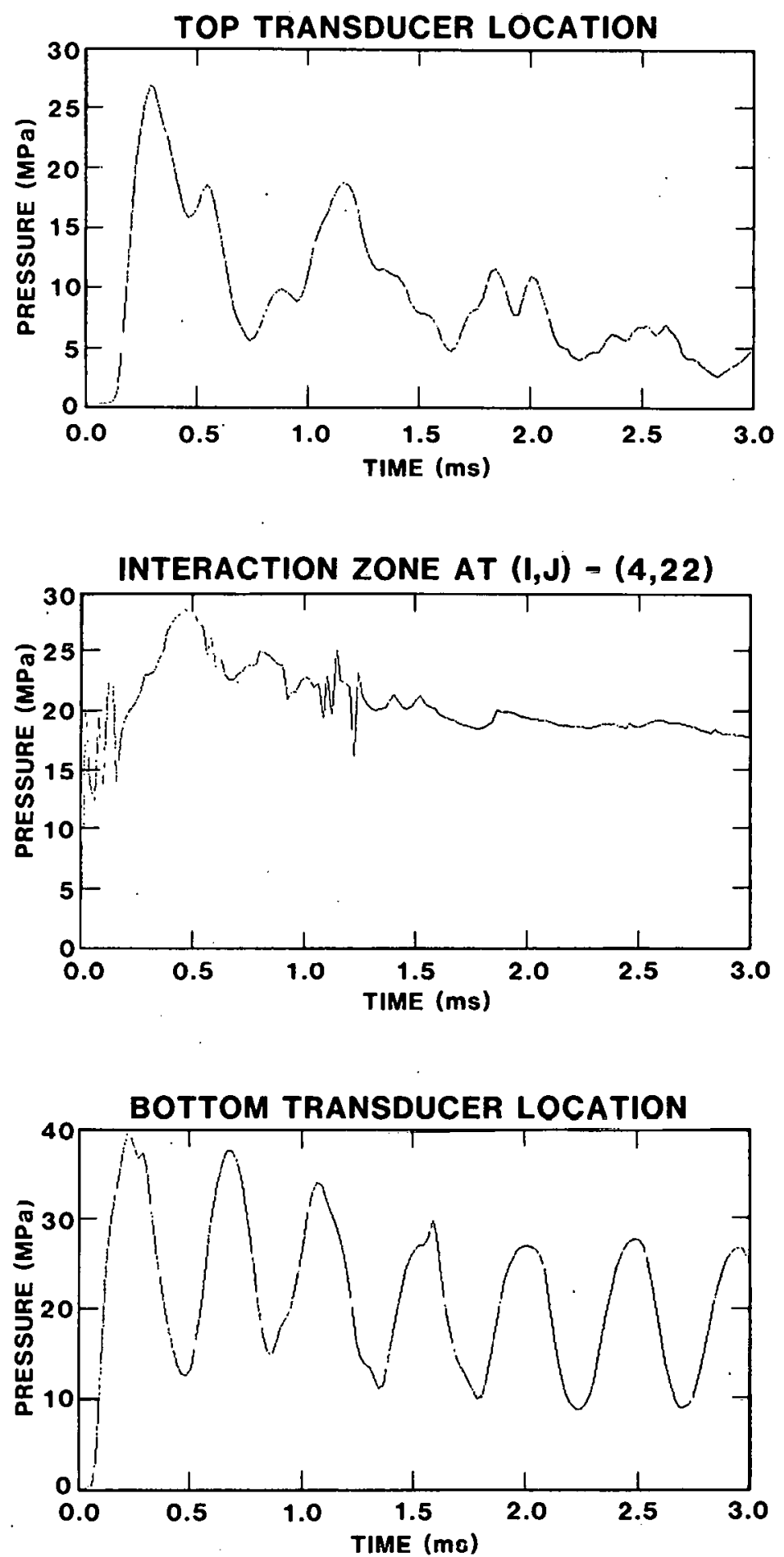

Figure A-6. Calculated Pressure Histories - Case 5 

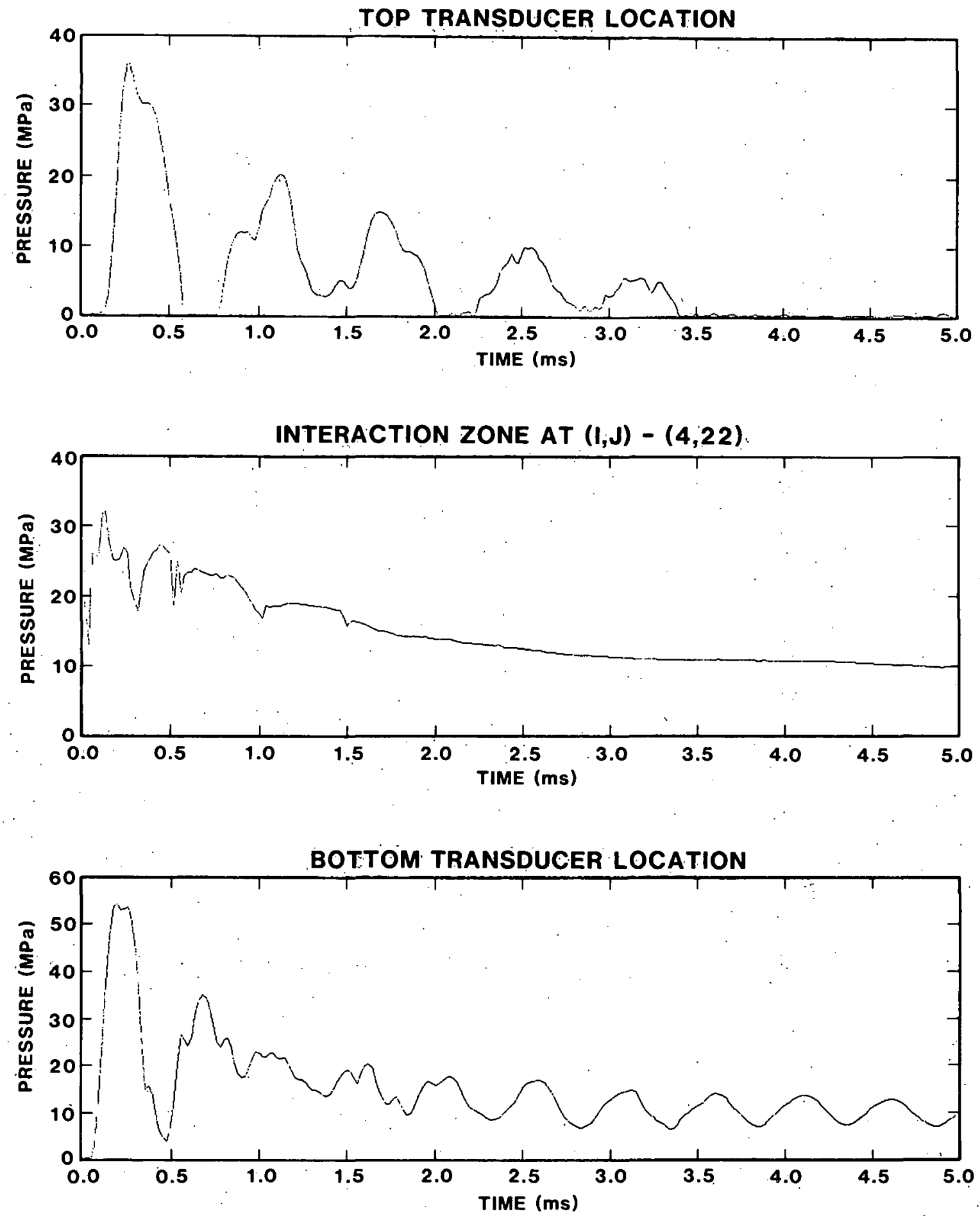

Figure A-7. Calculated Pressure Histories - Case 6 

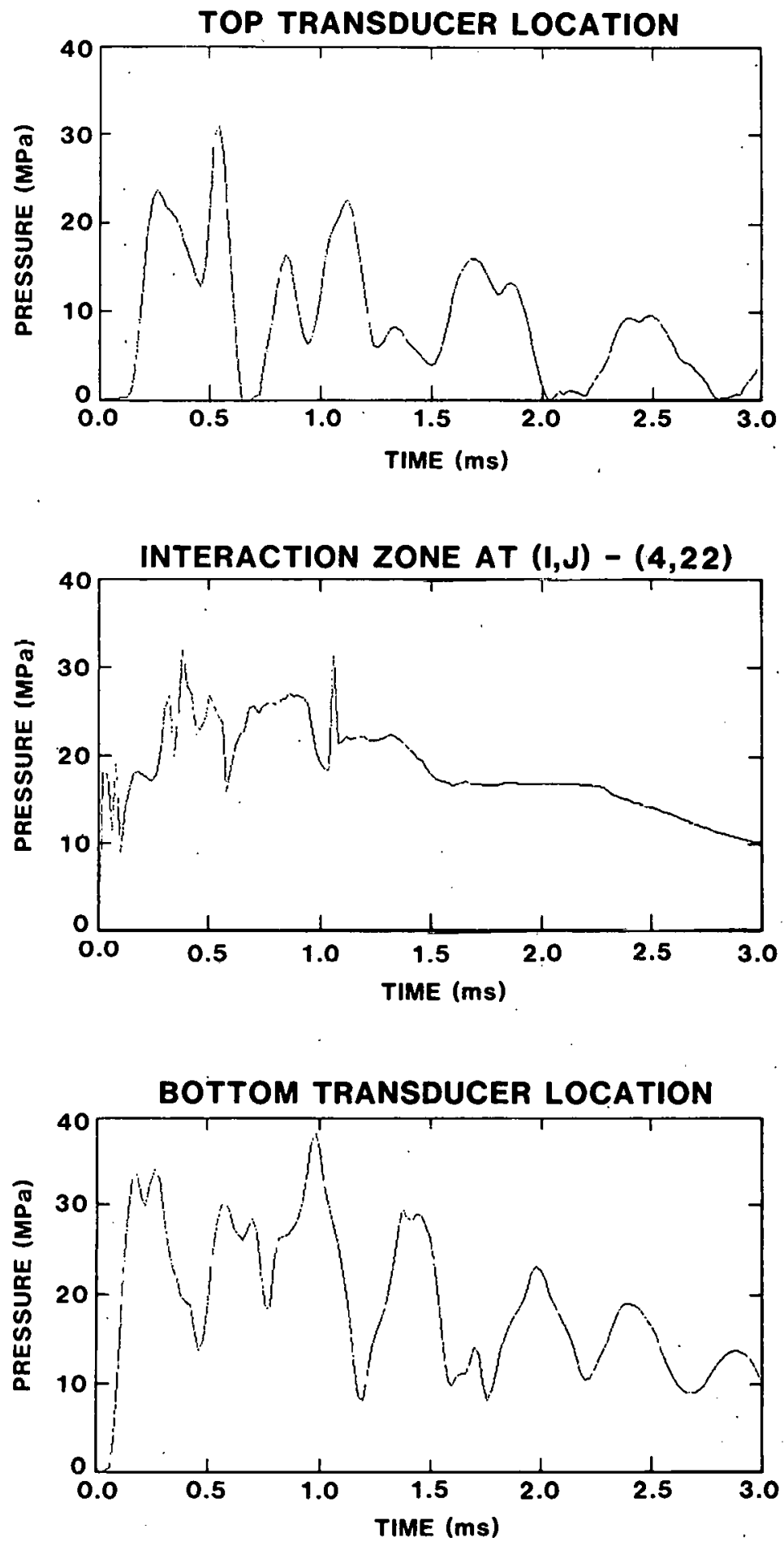

Figure A-8. Calculated Pressure Histories - Case 7. 

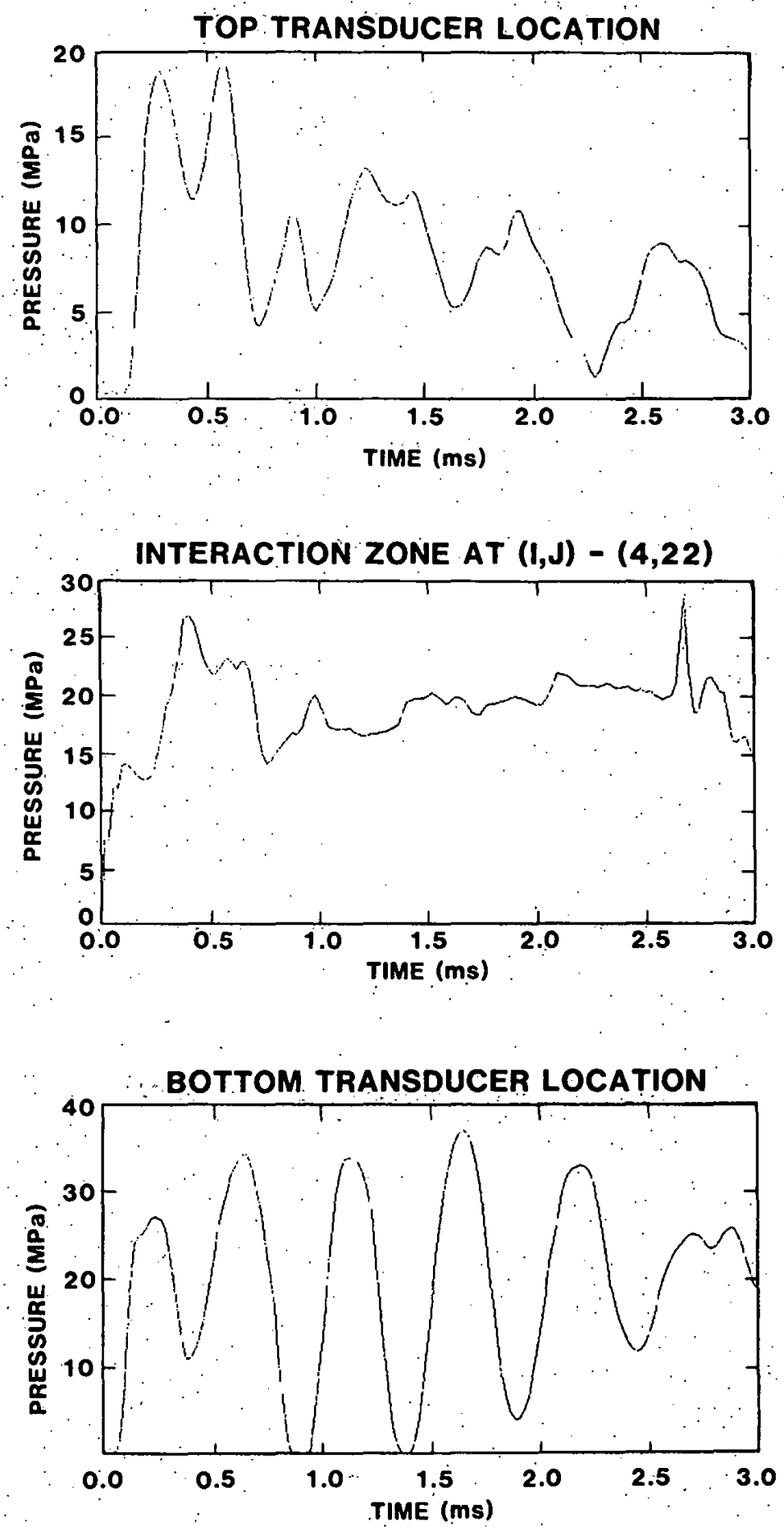

Figure A-9. Calculated Pressure Histories - Case 8 


\section{TOP TRANSDUCER LOCATION}

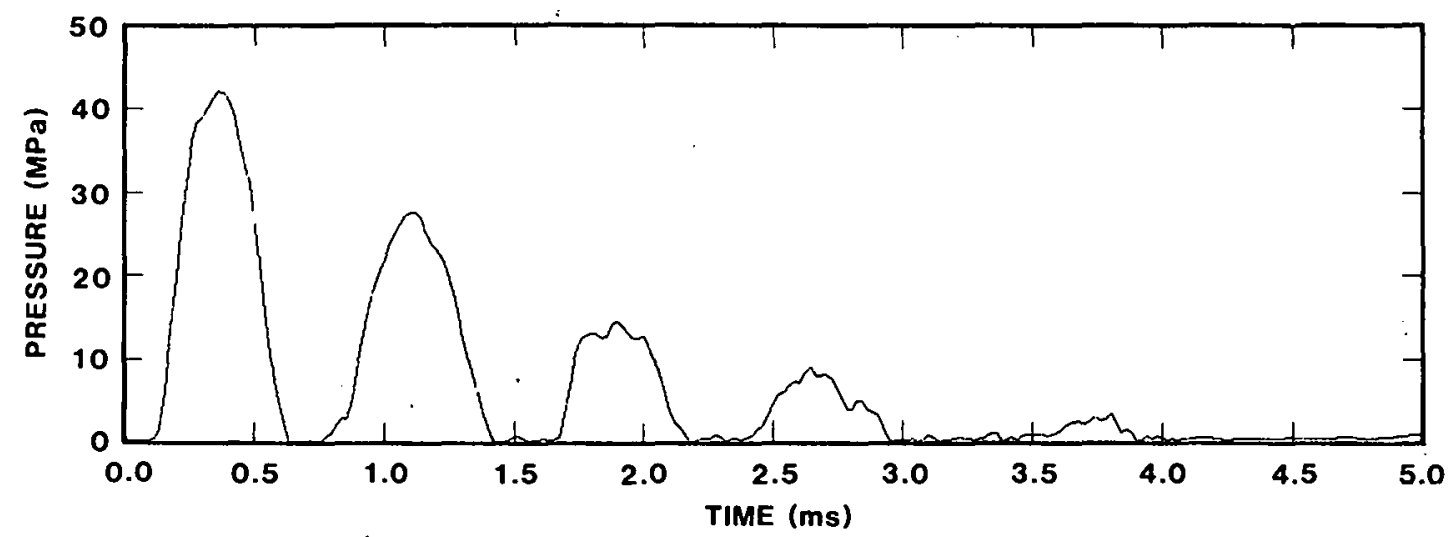

INTERACTION ZONE AT $(1, \mathrm{~J})-(4,22)$

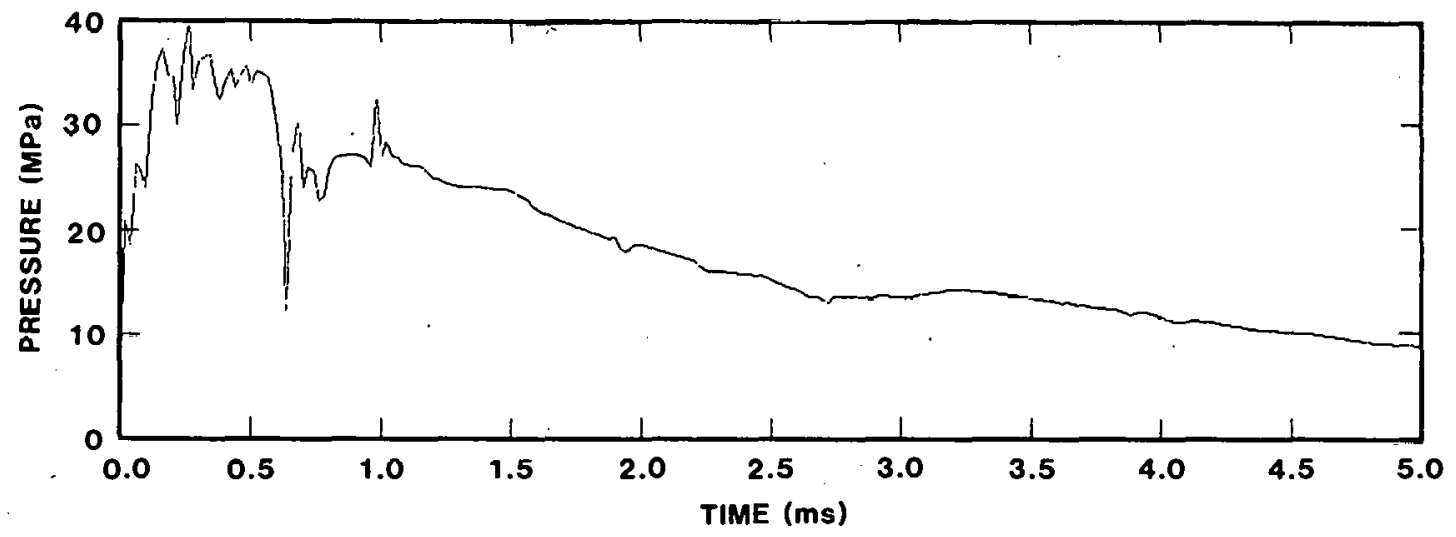

BOTTOM TRANSDUCER LOCATION

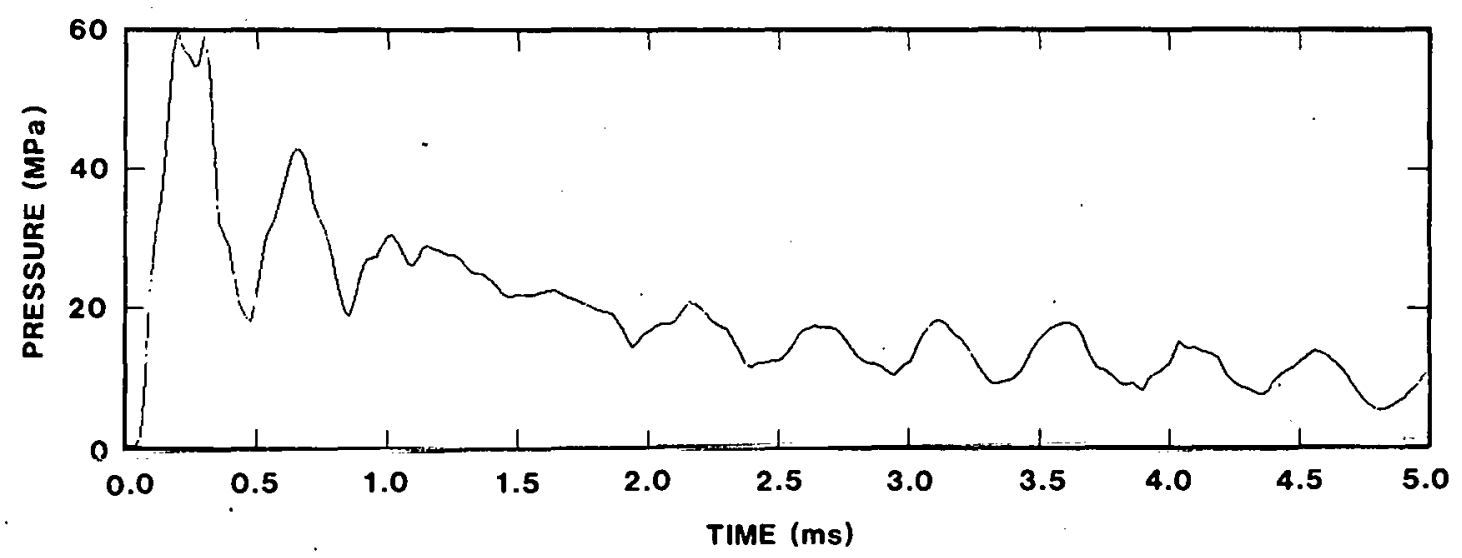

Figure A-10. Calculated Pressure Historiec - Cajc 0 

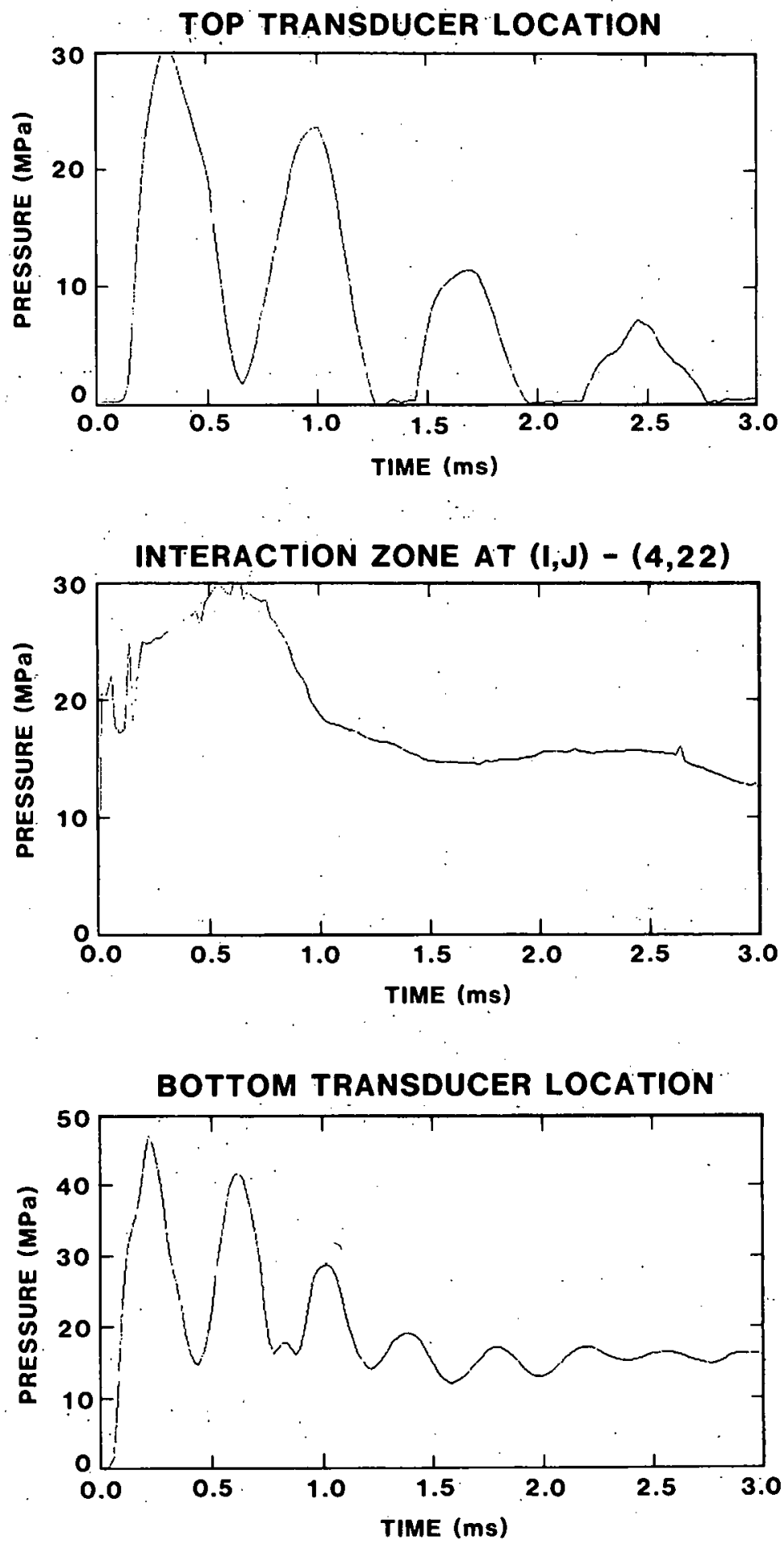

Figure A-11. Calculated Pressure Histories - Case 10 

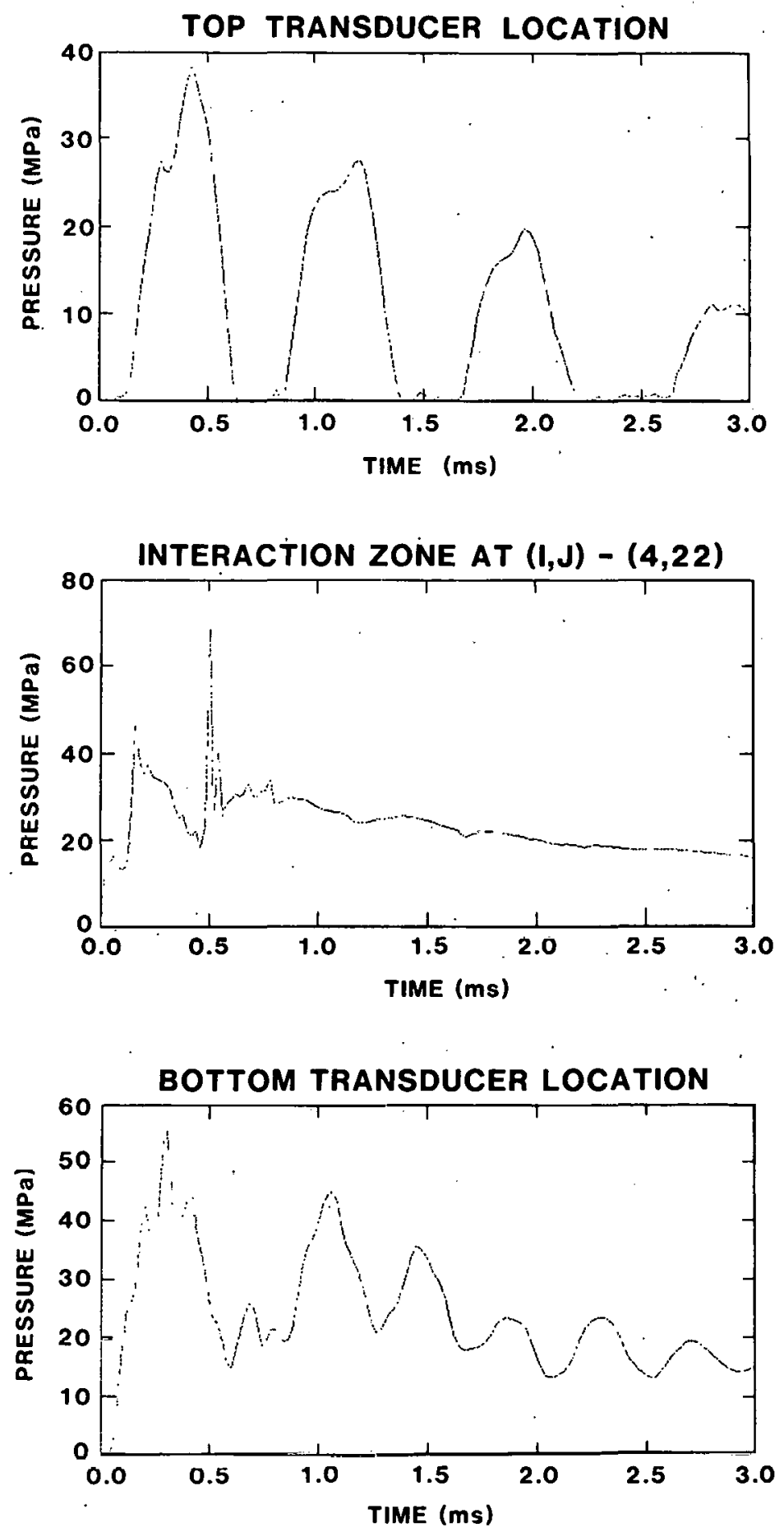

Figure A-12. Calculated Pressure Histories - Case 11 

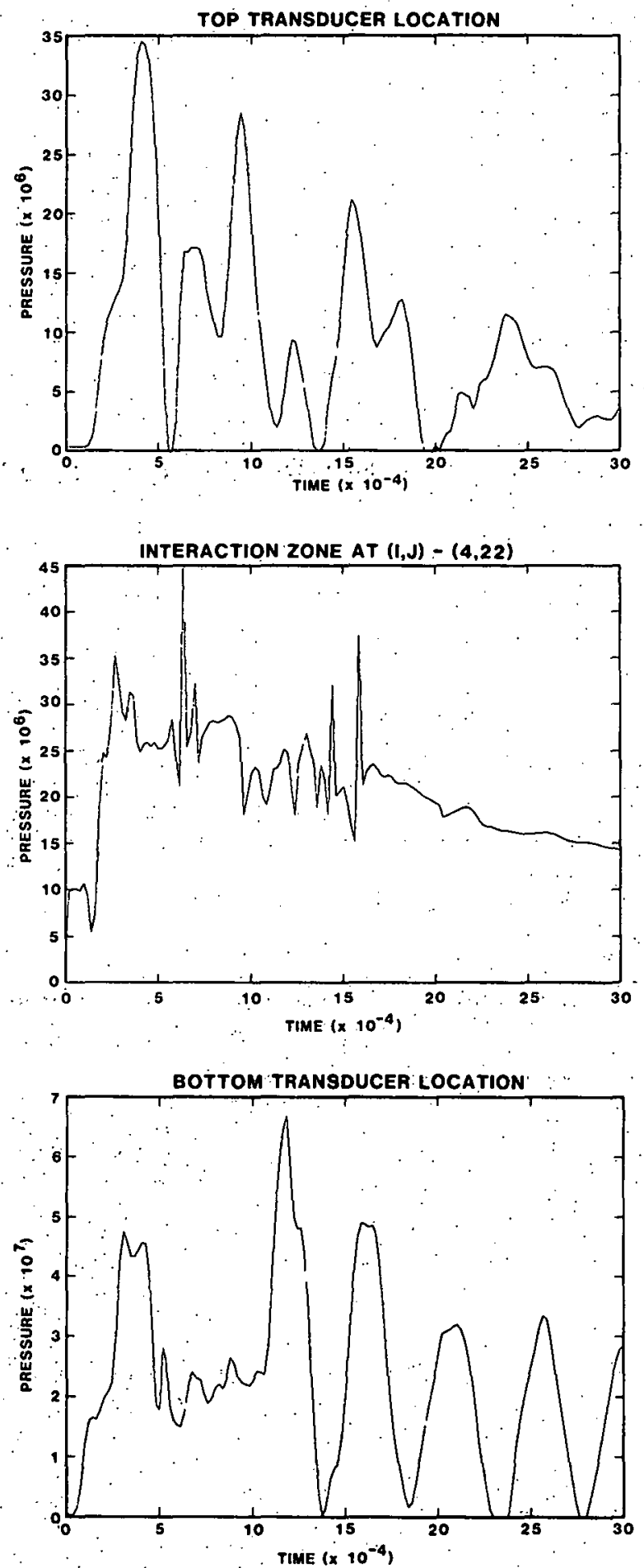

Figure A-13. Calculated Pressure Histories - Case 12 
TOP TRANSDUCER LOCATION
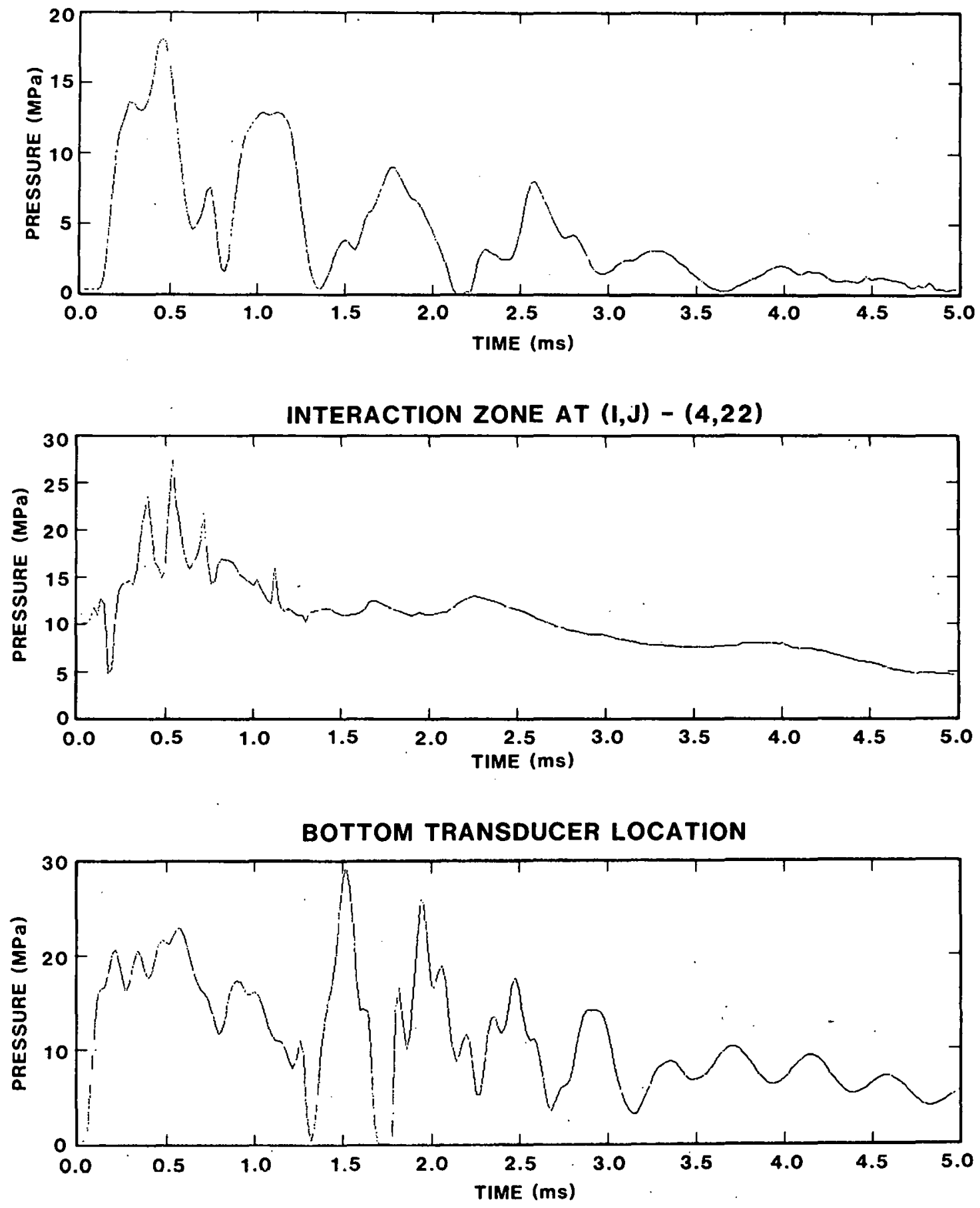

Flgure A-14. Calculated Fressure Histories - Case 13 

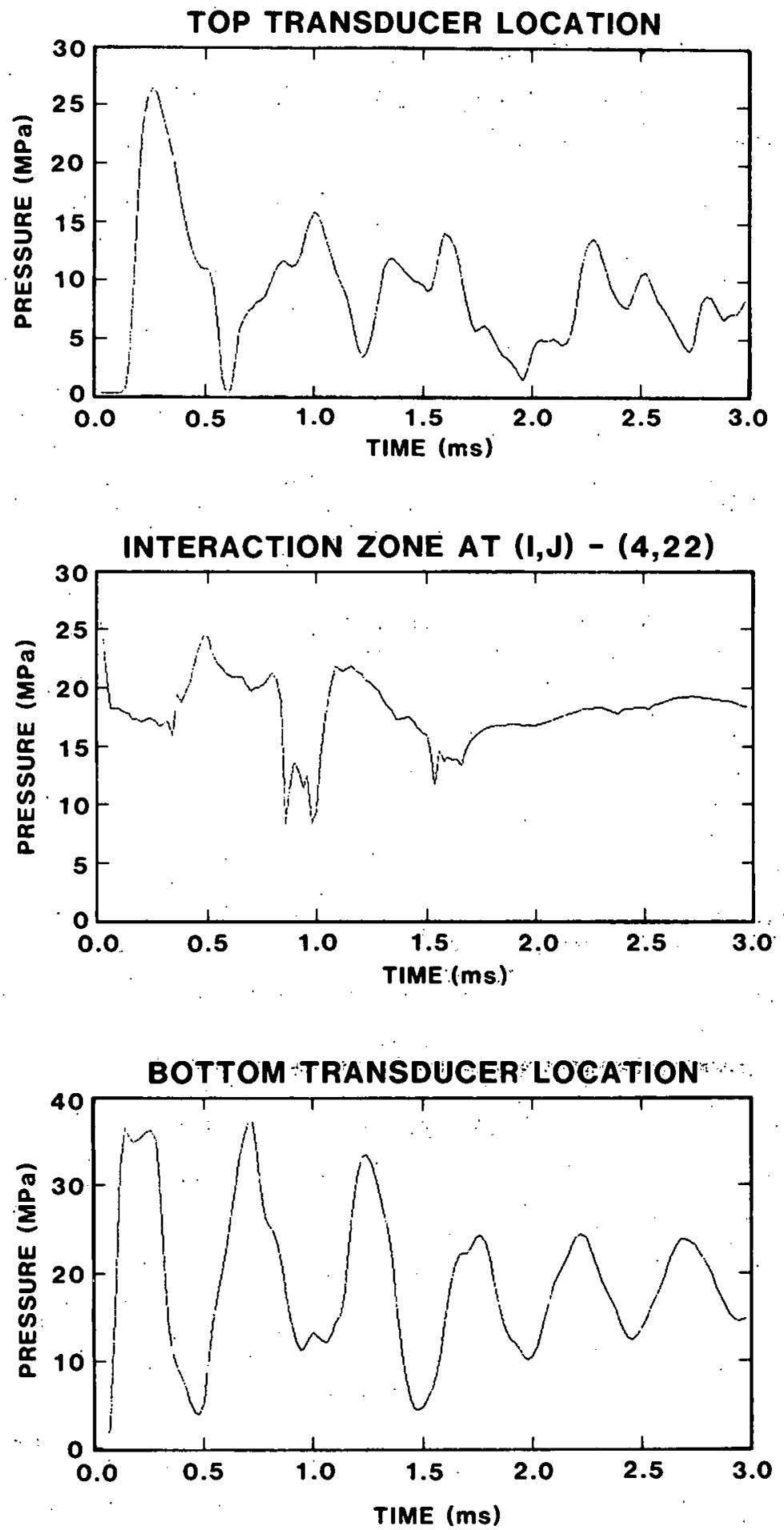

Figure A-15. Calculated Préssure Histories - Case 14 

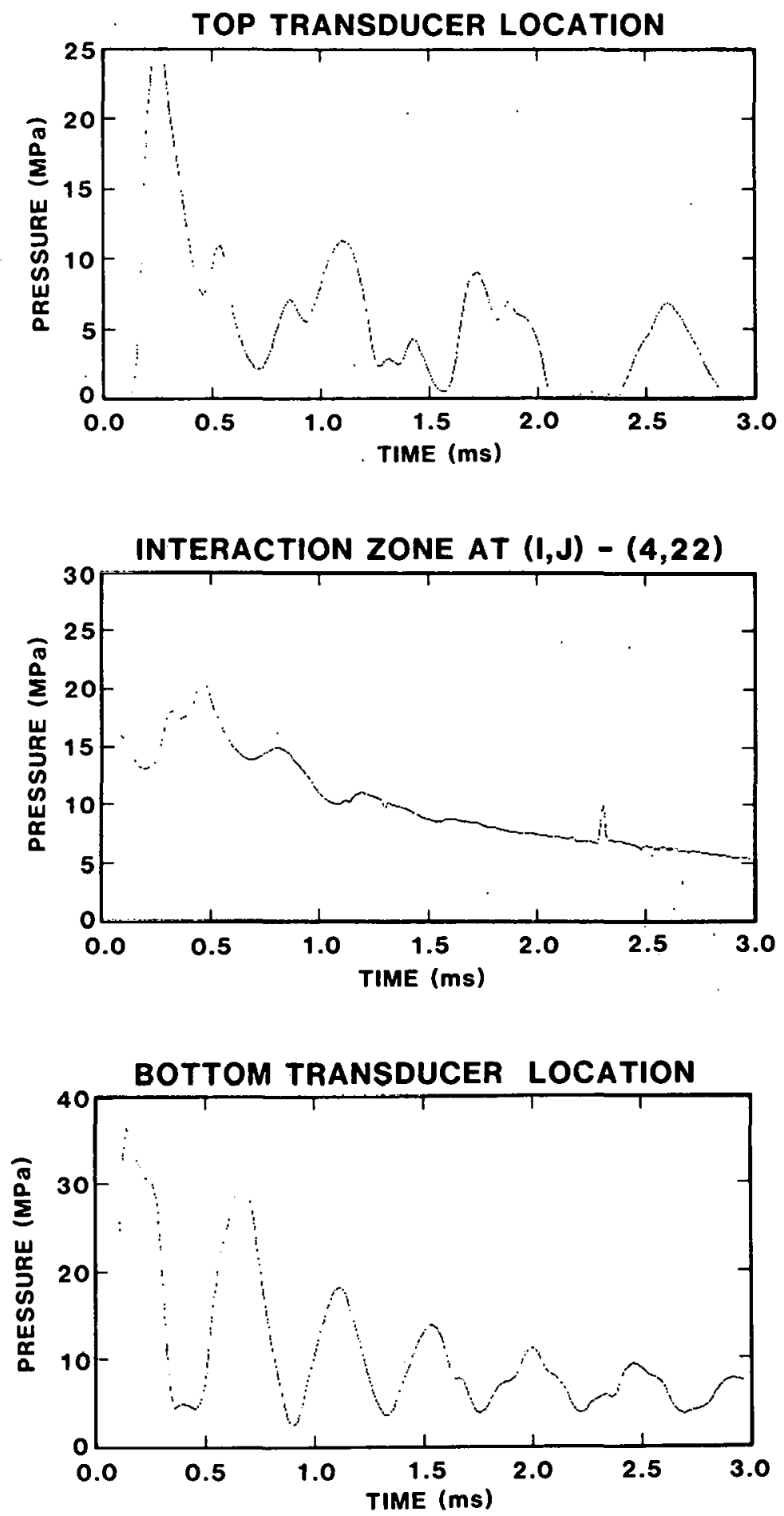

Figure A-16. Calculated Pressure Histories - Casè 15 


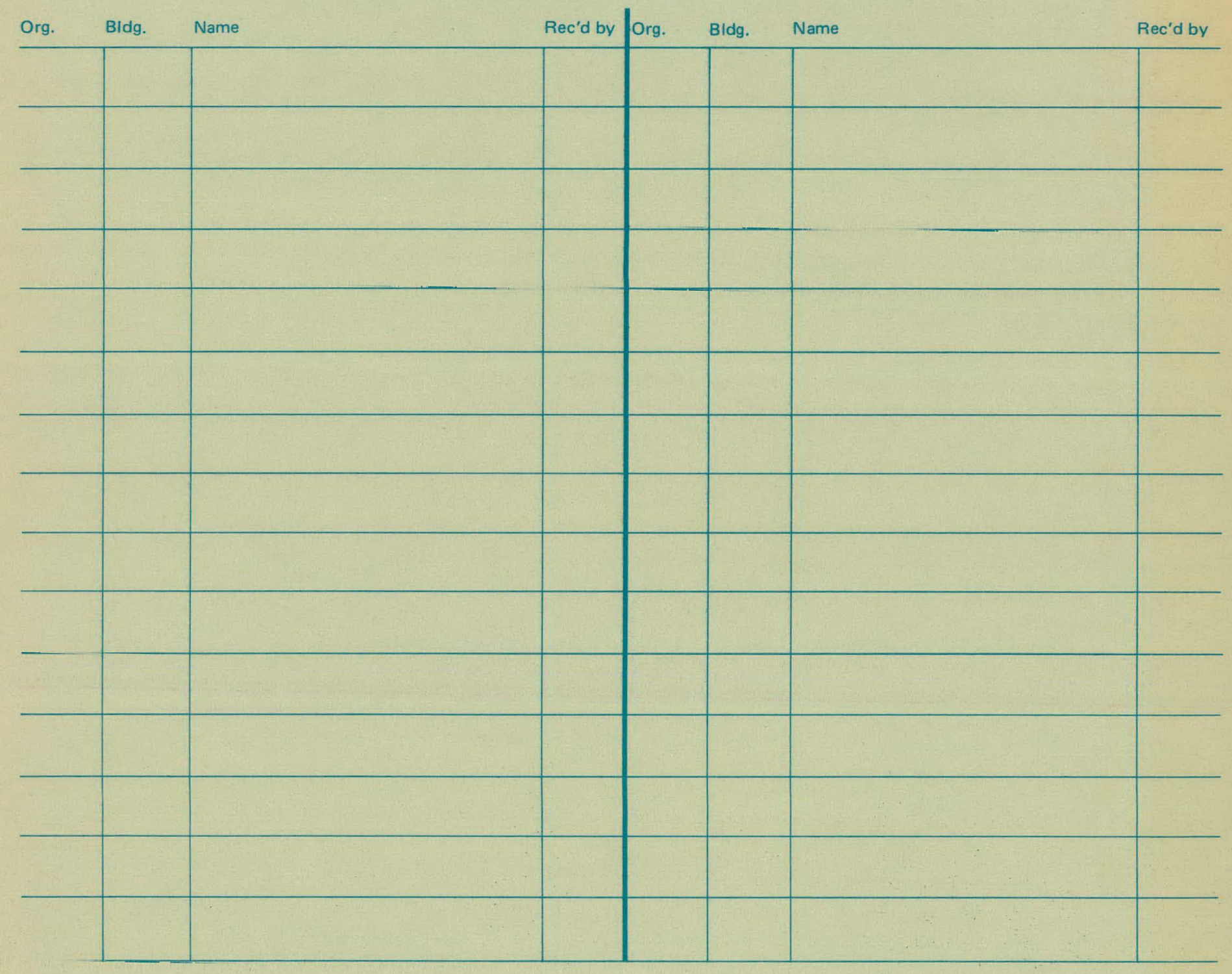

